\title{
ON THE PERFORMANCE OF HIGHER ORDER THEORIES FOR TRANSIENT DYNAMIC ANALYSIS OF SANDWICH AND COMPOSITE BEAMS
}

\author{
S. R. Marur $\dagger$ and T. Kant $\ddagger$ \\ $\dagger$ CSS Foundation for Research in Finite Elements, B4/4, Vaigai Nagar, Madurai-625 016, India \\ $\ddagger$ Department of Civil Engineering, Indian Institute of Technology, Powai, Bombay-400 076, India
}

(Received 24 September 1993)

\begin{abstract}
Higher-order shear-deformable refined theories, based on isoparametric elements, are adopted for transient dynamic analysis of symmetric and unsymmetric sandwich and composite beam constructions. These shear-correction coefficient free theories model cross sectional warping using nonlinear variation of inplane displacements across the depth. They also incorporate transverse shear stress in the formulation. A special lumping scheme is employed for the evaluation of diagonal mass matrix, and a central difference scheme is used for carrying out the integration of the equation of motion, to obtain the response history. Through numerical experiments, the efficacy of higher-order models in predicting displacements and stress, resultants over from the first-order theory, with respect to time, is clearly brought out in this paper. (C) 1997 Elsevier Science Ltd.
\end{abstract}

\section{INTRODUCTION}

\subsection{The need for refined theories}

The study of laminated composite and sandwich material constructions is a fertile area of research among aero-industries and space research establishments. This is due to the ease and advantage of such materials: with a choice of different fibre materials, orientation and stacking sequences, the behaviour pattern of either isotropic or orthotropic or anisotropic material could be achieved. The resultant laminate could then be made with the required stiffness, strength to weight ratios and damage tolerance as well as superior fatigue response characteristics.

These materials, on the other hand, are not devoid of problems, such as delamination at free edges due to interlaminar normal stresses and low lamina strength, cross sectional warping including the core, transverse shear effects etc. Thus, any analysis of such constructions would only be realistic and accurate when the models employed are capable of addressing these issues and providing solutions to these problems.

\subsection{Classical theory}

In addition to the above, the literature on beam formulations reveals that the Euler-Bernoulli theory has been the most prevalent for the transient dynamic analysis of beams and arches [1] and frames [2-6]. The major handicap with this theory is that it neglects the transverse shear strain completely and hence gets restricted to sections with high aspect ratios only.

\subsection{First-order theory}

The incorporation of transverse shear deformation into the governing equation by Timoshenko [7], was the first step towards the first-order shear deformation theory. Early versions of beam finite elements with the inclusion of rotary inertia and shear effects were reported by McCallay [8] and Archer [9]. Kapur [10] proposed a Timoshenko element with independent cubic polynomials for transverse displacements due to bending and shear. Two versions of the Timoshenko element were published, with cubic variation of transverse displacement and rotation of neutral axis [11, 12].

Different orders of interpolation for $w$ and 0 were employed in the development of shear deformable elements $[13,14]$. Both $w$ and $\theta$ and their respective spatial derivatives were considered as nodal degrees of freedom by Thomas and Abbas [15] for their version of the Timoshenko element. This theory was employed for transient dynamic analysis of elastic and elastoplastic beams and frames using $\mathrm{C}^{0}$ elements for comparison with that of Euler-Bernoulli theory using $C^{\prime}$ elements by Kant and Marur [16]. The shortcomings in this theory are the assumption that the shear strain remains constant across the thickness, and the need for a problem-dependent shear-correction coefficient.

\subsection{Second-, third- and fourth-order theories}

A second-order theory with two constants, one depending on the cross sectional warping and the other on the transverse direct stress, was proposed by Stephen and Levinson [17]. Heyliger and Reddy [18] 
proposed a third-order theory and its refined version, with transverse normal stress components, was reported later [19]. An attempt towards a fourthorder beam theory with the inclusion of transverse shear strain and warping of cross section was made by Levinson [20] and an improved version of the same was subsequently proposed by Rychter [21].

\subsection{Higher-order theory}

A higher-order model, as a further development of fourth-order theory and based on Hamilton's principle, was reported by Bickford [22] for the dynamic analysis of elastic beams. Reddy [23] also formulated a higher-order model, incorporating the transverse shear stress with $\mathrm{C}^{\prime}$ elements. Kant and Gupta [24] proposed a refined higher-order model, with the inclusion of transverse shear and normal stress components with simple $\mathrm{C}^{0}$ elements, for the static and free vibration analysis of isotropic beams. Later, the higher order models were extended to the static analysis of composite and sandwich beams, both without [25], and with [26], the transverse normal strain components.

\subsection{Higher-order theory for transient dynamics}

While the Euler-Bernoulli theory is very much restricted to thin sections, the first-order theory always requires a problem-dependent factor. Moreover, this theory cannot model the cross sectional warping, an important element in modelling composites. The second-order theory [17] needs two factors, making this thcory a problem-dependent one also. The third-order theory [18] has the basic disadvantage of $\mathrm{C}^{\prime}$ continuity, while the fourth-order theory [20] has been formulated exclusively for beams with narrow rectangular cross sections and, hence, cannot be directly applied to other beams with arbitrary cross sections. The higher-order theory [23] also retains the $\mathrm{C}^{\prime}$ continuity.

The higher-order models of Kant and his co-workers [24-26], however, are free of all these shortcomings and are based on isoparametric elements. Moreover, they assume cubic axial strain, quadratic transverse shear strain and linear transverse normal strain components in order to capture the behaviour of composite and sandwich constructions.

While the analysis of such structures requires a tool like higher-order theory, the picture that emerges from the study of the literature clearly indicates the wider usage of Euler-Bernoulli and first-order shear deformation theories. In addition, the untapped potential of higher-order models for the exploration of transient dynamic behaviour of composites and sandwiches is indicated.

Hence, three higher-order models are proposed in this paper, in order to investigate the mechanics of composite and sandwich beams, undergoing transient dynamic deformations.

\section{HIGHER-ORDER THEORIES AND FORMULATIONS}

\subsection{Higher-order models}

The higher-order displacement model, based on the Taylor's series expansion [27] of the displacement components, is given by

$$
\begin{gathered}
u(x, z, t)=u_{0}(x, t)+z \theta_{x}(x, t) \\
+z^{2} u_{0}^{*}(x, t)+z^{3} \theta_{x}^{*}(x, t), \\
w(x, z, t)=w_{0}(x, t),
\end{gathered}
$$

where $u_{0}$ and $w_{0}$ are axial and transverse displacements, in the $x-z$ plane at time $t, \theta_{x}$ is the rotation of cross section about the $y$-axis, and $u_{0}^{*}$ and $\theta_{x}^{*}$ are higher-order terms arising out of Taylor series expansion and defined at the neutral axis.

The possible variations of axial displacement given by eqn (1) are

$$
u(x, z, t)=u_{0}(u, t)+z \theta_{x}(x, t)+z^{2} u_{0}^{*}(x, t)
$$

and

$$
u(x, z, t)=u_{0}(x, t)+z \theta_{x}(x, t)+z^{3} \theta_{x}^{*}(x, t)
$$

The models given by eqns (3), (4) and (1) can be designated as Higher Order Beam Theory 4a, HOBT4b and HOBT5, respectively, with the transverse displacement remaining the same for all the three models, as given by eqn (2). The following presentation is based on HOBT5, as the other two models are the special cases of HOBT5 itself.

\subsection{Total energy}

The total energy of a system can be given by

$$
L=T-\Pi
$$

and

$$
\Pi=U_{\mathrm{s}}-W_{\mathrm{e}}
$$

where $U_{\mathrm{s}}$ is the internal strain energy, $W_{\mathrm{e}}$ is the work done by the external forces, and $T$ is the kinetic energy.

Equation (6) can be rewritten as

$$
L=\frac{1}{2} \int \dot{\mathbf{u}}^{\mathrm{i}} \rho \dot{\mathbf{u}} \mathrm{d} v-\left[\frac{1}{2} \int \epsilon^{\mathbf{l}} \boldsymbol{\sigma} \mathrm{d} v-\int \mathbf{u}^{\mathbf{t}} \mathbf{P} \mathrm{d} x\right]
$$

where

$$
\begin{gathered}
\mathbf{u}=[u w]^{\mathrm{k}}, \quad \dot{\mathbf{u}}=[\dot{u} \dot{w}]^{\mathrm{t}}, \\
\epsilon=\left[\epsilon_{x} \gamma_{x z}\right]^{\mathrm{k}}, \quad \boldsymbol{\sigma}=\left[\sigma_{x} \tau_{x z}\right]^{\mathrm{k}}, \\
\mathbf{P}=\left[p_{x} p_{z}\right]^{\mathrm{k}} .
\end{gathered}
$$




\subsection{Internal strain energy}

Now the displacements can be written as

$$
\mathrm{u}=\underline{Z}_{\mathrm{d}} \mathrm{d}
$$

where

$$
\begin{gathered}
\mathbf{u}=[u w]^{\mathrm{t}} \\
\mathbf{d}=\left[u_{0} w_{0} \theta_{x} u_{0}^{*} \theta_{x}^{*}\right]^{\mathrm{t}}
\end{gathered}
$$

and

$$
\underline{\boldsymbol{Z}}_{\mathrm{d}}=\left[\begin{array}{ccccc}
1 & 0 & z & z^{2} & z^{3} \\
0 & 1 & 0 & 0 & 0
\end{array}\right]
$$

The strains are written as

$$
\begin{gathered}
\epsilon_{x}=\epsilon_{x+1}+z^{2} \epsilon_{x \mathbf{0}}^{*}+z K_{x}+z^{3} K_{x}^{*} \\
\gamma_{x z}=\phi+z^{2} \phi^{*}+z K_{x z},
\end{gathered}
$$

where

$$
\begin{gathered}
{\left[\epsilon_{x 0} \epsilon_{x 0}^{*} K_{x} K_{x}^{*}\right]=\left[u_{0, x} u_{0, x}^{*} \theta_{x, y} \theta_{x, r}^{*}\right]} \\
{\left[\phi \phi^{*} K_{x z}\right]=\left[\left(w_{0, x}+\theta_{x}\right) 3 \theta_{x}^{*} 2 u_{0}^{*}\right],}
\end{gathered}
$$

and can be expressed in the matrix form as

$$
\boldsymbol{\epsilon}=\underline{Z}_{s} \bar{\epsilon}
$$

where

$$
\begin{gathered}
\overline{\boldsymbol{\epsilon}}=\left[\epsilon_{x 0} \epsilon_{x a}^{*} K_{x} K_{x}^{*} \mid \phi \phi^{*} K_{x z}\right] \\
\underline{\mathbf{Z}}_{s}=\left[\begin{array}{cccc|ccc}
1 & z^{2} & z & z^{3} & 0 & 0 & 0 \\
0 & 0 & 0 & 0 & 1 & z^{2} & z
\end{array}\right] .
\end{gathered}
$$

The constitutive relation of a typical lamina is given by

$$
\sigma=\underline{\mathrm{D}} \boldsymbol{\epsilon}
$$

where

$$
\begin{gathered}
\underline{\mathbf{D}}=\left[\begin{array}{cc}
E & 0 \\
0 & G
\end{array}\right], \\
\boldsymbol{\sigma}=\left[\sigma_{r} \tau_{r=}\right]^{\prime}
\end{gathered}
$$

The internal strain energy, after carrying out the integration across the cross section, becomes

$$
U_{\mathrm{s}}=\frac{b}{2} \int_{1} \bar{\epsilon} \bar{\sigma} \mathrm{d} x
$$

where

$$
\overline{\boldsymbol{\sigma}}=\underline{\mathbf{D}} \overline{\boldsymbol{\epsilon}}
$$

The stress resultants are given by

$$
\overline{\boldsymbol{\sigma}}=\left[N_{x} N_{x}^{*} M_{x} M_{x}^{*} \mid Q Q^{*} S\right]^{1}
$$

and

$$
\underline{\mathbf{D}}=\int_{z} \underline{\mathbf{Z}}_{s}^{\mathbf{D} \mathbf{Z}} \underline{\mathbf{Z}}_{\mathrm{s}} \mathrm{d} z
$$

$$
=\sum_{L=1}^{N L} \int_{h_{L-1}}^{h_{L}} \underline{\mathbf{Z}}_{s}^{\mathrm{D}} \underline{\mathbf{Z}}_{\mathrm{s}} \mathrm{d} z
$$

which appears in a matrix form as,

$$
\underline{\mathbf{D}}=\left[\begin{array}{cc|c}
\underline{\mathbf{D}}_{\mathrm{m}} & \underline{\mathbf{D}}_{\mathrm{c}} & 0 \\
\underline{\mathbf{D}}_{\mathrm{c}}^{\mathrm{c}} & \underline{\mathbf{D}}_{\mathrm{b}} & \\
\hline 0 & & \underline{\mathbf{D}}_{\mathrm{s}}
\end{array}\right]
$$

where $N L$ stands for the (total) number of layers of the cross section,

$$
\begin{gathered}
\underline{\mathbf{D}}_{\mathrm{m}}=\sum_{L=1}^{N L} E_{L}\left[\begin{array}{ll}
H_{1} & H_{3} \\
H_{3} & H_{5}
\end{array}\right] \quad \underline{\mathbf{D}}_{\mathrm{c}}=\sum_{L=1}^{N L} E_{L}\left[\begin{array}{ll}
H_{2} & H_{4} \\
H_{4} & H_{6}
\end{array}\right] \\
\underline{\mathbf{D}}_{\mathrm{b}}=\sum_{L=1}^{N L} E_{L}\left[\begin{array}{ll}
H_{3} & H_{5} \\
H_{5} & H_{7}
\end{array}\right] \\
\underline{\mathbf{D}}_{\mathrm{s}}=\sum_{L=1}^{N L} G_{L}\left[\begin{array}{lll}
H_{1} & H_{3} & H_{2} \\
& H_{5} & H_{4} \\
\text { sym. } & & H_{3}
\end{array}\right] \quad(16 \mathrm{a})
\end{gathered}
$$

and

$$
H_{k}=\left(h_{L}^{k}-h_{L-1}^{k}\right) / k, \quad k=1 \ldots 7 .
$$

\subsection{Kinetic energy}

The kinetic energy can be expressed using eqn (8) as

$$
T=\frac{1}{2} \int_{1} d^{\prime} \underline{m} d \mathrm{~d} x,
$$


where

$$
\begin{gathered}
\underline{\mathbf{m}}=b \int_{z} \underline{\mathbf{Z}}_{\mathrm{d}}^{\mathrm{t}} \rho_{L} \underline{\mathbf{Z}}_{\mathrm{d}} \mathrm{d} z \\
=b \sum_{L=1}^{N_{L}} \int_{h_{L-1}}^{h_{L}} \underline{\mathbf{Z}}_{\mathrm{d}}^{\mathrm{t}} \rho_{L} \underline{\mathbf{Z}}_{\mathrm{d}} \mathrm{d} z .
\end{gathered}
$$

Here, $\rho_{L}$ is the mass density of a particular layer.

The diagonal elements of the matrix given by the above equation, corresponding to any node $i$, can be expressed by

$$
\underline{\mathbf{m}}_{i i}=b \sum_{L=1}^{N L} \int_{h_{L-1}}^{h_{L}}\left[11 z^{2} z^{4} z^{6}\right] \rho_{L} \mathrm{~d} z
$$

\subsection{Work potential}

Similarly, the external work done is modified using eqn (8) as

$$
W_{\mathrm{e}}=\int_{1} \mathbf{d} \mathbf{P} \mathrm{d} x
$$

where

$$
\mathbf{P}=\underline{\mathbf{Z}}_{\mathrm{d}}^{\mathrm{t}} \mathbf{P}
$$

or

$$
\mathbf{P}=\left[p_{* 0} p_{z 0} m_{x 0} P_{.00}^{*} m_{x 0}^{*}\right]^{\mathrm{t}}
$$

Now, the total energy reappears with eqns (13), (17) and (19) as

$$
L=\frac{1}{2} \int_{1} \mathbf{d}^{\prime} \underline{\underline{m}} \mathbf{d} \mathrm{d} x-\left[\frac{\mathrm{b}}{2} \int_{1} \bar{\epsilon} \overline{\bar{\sigma}} \mathrm{d} x-\int_{1} \mathrm{~d} \mathbf{P} \mathbf{P} \mathrm{d} x\right]
$$

\section{FINITE ELEMENT MODELLING}

In isoparametric formulations, the displacements within an element can be expressed in terms of its nodal displacements as

$$
\mathbf{d}=\mathbf{N} \mathbf{a}_{\mathrm{e}},
$$

where $a_{\mathrm{e}}$ is a vector containing nodal displacement vectors of an element, and is given by

$$
\mathbf{a}_{\mathbf{e}}=\left[\mathbf{d}_{1}^{\mathbf{t}} \mathbf{d}_{2}^{\mathrm{t}} \mathbf{d}_{3}^{\mathrm{t}} \ldots \mathbf{d}_{n}^{\mathrm{t}}\right]^{\mathrm{t}}
$$

and $\mathbf{N}$ is the shape function matrix.

Similarly, the strain within an element can be written as

$$
\overline{\boldsymbol{\epsilon}}=\underline{\mathbf{B}} \mathbf{a}_{\mathbf{e}}
$$

where $\mathbf{B}$ is the strain displacement matrix.

The non-zero elements of $\underline{\mathbf{B}}$ corresponding to a particular node $i$ can be given as

$$
\begin{aligned}
& B_{11}=B_{24}=B_{33}=B_{45}=B_{52}=N_{i, x} \\
& B_{53}=N_{i} ; \quad B_{65}=3 N_{i} ; \quad B_{74}=2 N_{i} .
\end{aligned}
$$

With eqns (21) and (22), total energy can be written as

$$
\begin{aligned}
L=\frac{1}{2} \dot{\mathbf{a}}_{\mathrm{e}}^{\mathrm{t}} \int_{1} \underline{\mathbf{N}^{\mathrm{t}}} \underline{\underline{\mathbf{m}} \mathbf{N}} \mathrm{d} x \dot{\mathbf{a}}_{\mathrm{e}}-\left[\frac{\mathrm{b}}{2} \mathbf{a}_{\mathrm{e}}^{\mathrm{t}} \int_{1} \underline{B}^{\mathrm{t}} \overline{\mathrm{\sigma}} \mathrm{d} x-\mathbf{a}_{\mathrm{e}}^{\mathrm{t}} \int_{1} \underline{\mathbf{N}} \mathbf{P} \mathrm{d} x\right] \\
=\frac{1}{2} \dot{\mathbf{a}}_{\mathrm{e}}^{\mathrm{t}} \int_{1} \underline{\mathbf{N}} \underline{\underline{\mathbf{m}} \mathbf{N}} \mathrm{d} x \dot{\mathbf{a}}_{\mathrm{e}}-\left[\frac{\mathrm{b}}{2} \mathbf{a}_{\mathrm{e}}^{\mathrm{t}} \int_{1} \underline{\mathbf{B}^{\mathrm{t}}} \underline{\mathbf{D B}} \mathrm{d} x \mathbf{a}_{\mathrm{e}}\right.
\end{aligned}
$$$$
\left.-\mathbf{a}_{\mathrm{e}} \int_{1} \underline{\mathbf{N}} \mathbf{P} \mathrm{d} x\right]
$$

Applying Hamilton's principle on $L$, we get the equation of motion as

$$
\underline{\mathbf{M}} \ddot{\mathbf{d}}+\underline{\mathbf{K}} \mathbf{d}=\mathbf{f}(t)
$$

where

$$
\begin{aligned}
& \underline{\mathbf{M}}=\int_{1} \underline{\mathbf{N}} \underline{\mathbf{m} \mathbf{N}} \mathrm{d} x \\
& \underline{\mathbf{K}}=b \int_{1} \underline{\mathbf{B}} \underline{\mathbf{D B}} \mathrm{d} x \\
& \mathbf{f}(t)=\int_{1} \underline{\mathbf{N}} \mathbf{P} \mathrm{d} x .
\end{aligned}
$$

\subsection{Mass matrix evaluation}

The consistent mass matrix is evaluated as

$$
\underline{\mathbf{M}_{e}}=\sum_{g=1}^{N G} W_{g} \underline{\mathbf{N}} \underline{\underline{\mathbf{m}} \mathbf{N}}|J|
$$

where $N G$ is the (total) number of gauss points (four in this case), $W_{g}$ is the weighing coefficient and $|J|$ is the determinant of Jacobian.

If the total mass of an element can be given by

$$
m_{\mathrm{t}}=\int_{\mathrm{r}} \rho \mathrm{d} v
$$

and the sum of the diagonal coefficients of the consistent mass matrix given by eqn (26), corresponding to any translational degree of freedom alone, is termed as $\Sigma m_{\mathrm{tr}}$, then the specially lumped mass 
matrix can be obtained [28] by scaling all the diagonal elements of the consistent mass matrix as

$$
\ddot{n}_{i i}=\bar{m}_{i i}^{*} m_{\mathrm{t}} / \Sigma m_{\mathrm{tr}}
$$

and making all the off-diagonal terms of the consistent mass matrix zero.

\subsection{Stiffness matrix evaluation}

The stiffness matrix can be evaluated as

$$
\underline{\mathbf{K}}_{\mathrm{e}}:=b \sum_{g=1}^{N G} W_{g} \underline{\mathbf{B}} \underline{\mathbf{D} \mathbf{B}}|J|
$$

where total number of Gauss points are four for bending and three for shear terms evaluation.

\subsection{Load vector evaluation}

The consistent load vector, due to a uniformly distributed transverse load $p_{0}$, is given by

$$
\mathbf{f}(t)=\sum_{g=1}^{N G} W_{g} \mathbf{N} \overline{\mathbf{p}}|J|
$$

where

$$
\overline{\mathbf{p}}=\left[\begin{array}{lllll}
0 & p_{0} & 0 & 0 & 0
\end{array}\right] \text { and } N G=3 .
$$

\subsection{Solution of equation of motion}

The governing equation of motion is solved using the central difference predictor technique [29] to obtain the response history at different time steps.

\section{NUMERICAL EXAMPLES}

In order to test the proposed higher-order models, beams with both sandwich and composite constructions, subjected to transverse dynamic loadings, are considered in this study. Isoparametric cubic elements are employed to discretize the beams. All the experiments are carried out on an IBM compatible 486 computer on DOS in double precision.

A simply supported beam of 30 in long and unit width is discretized using four cubic elements. The length to depth ratio of the beam is five and is subjected to a transverse dynamic load of $300 \mathrm{lb} \mathrm{in}^{-1}$. The boundary conditions used for the simply supported case are as follows:

$$
u_{0}=w_{0}=u_{0}^{*}:=0 \quad \text { at } \quad x=0 \text { and } x=L .
$$

The quantities like $w(1 / 2,0), u(0, z), Q(0)$ and $M(1 / 2)$ are expressed with respect to time, in their own dimensions, with $u(0, z)$ being scaled by
-1 , while the following are non-dimensionalized as

$$
\bar{u}(0, z)=u(0, z) E_{z} /\left(-p_{0}\right)
$$

$$
\bar{\sigma}_{x}(1 / 2, z)=\bar{\sigma}_{x}(1 / 2, z) b /\left(-p_{0}\right)
$$

and expressed as the variation along the depth of cross section.

\section{Experiment 1}

First, a symmetric sandwich beam with $0 / 90 /$ core/ $90 / 0$ configuration is studied.

Data 1

Face sheets [30]: (top/bot)

$$
\begin{aligned}
\mathbf{E}_{x} & =0.1742 \times 10^{8} \mathrm{psi} \\
E_{z} & =0.1147 \times 10^{7} \mathrm{psi} \\
G_{x z} & =0.7983 \times 10^{6} \mathrm{psi}^{-3} \\
\rho & =0.1433 \times 10^{-3} \mathrm{lb} \mathrm{s}^{2} \mathrm{in}^{-4} \\
t_{f} & =0.3 \mathrm{in} .
\end{aligned}
$$

Core [31]:

$$
\begin{aligned}
G_{x z} & =0.2042 \times 10^{5} \mathrm{psi} \\
\rho & =0.3098 \times 10^{-5} \mathrm{lb} \mathrm{s}^{2} \mathrm{in}^{-4} \\
t_{c} & =4.8 \mathrm{in} \\
t_{c} / t_{f} & =8 .
\end{aligned}
$$

The cross section is split into six layers; top and bottom faces into two layers each and the core into two parts.

Figure 1 shows the transverse displacement response history. While HOBT5 and HOBT4b give identical values, which are almost three times higher than that of Timoshenko, the period of the response due to first-order theory is almost half its higherorder counterparts. HOBT4a predicts results which are stiffer than Timoshenko both in amplitude and period. A similar pattern is observed in the inplane response history in Fig. 2. The shear force at the left support of the simply supported beam is presented in Fig. 3. While higher order models predict higher amplitude and period than the first order model, HOBT4a is stiffer than Timoshenko. The midspan peak bending moment due to HOBT5 and HOBT4b is marginally less than Timoshenko while the higher-order period is nearly twice that of Timoshenko. HOBT4a is stiffer than Timoshenko as shown in Fig. 4.

The variation of inplane displacement along the depth is depicted in Fig. 5. While the first-order theory and HOBT4a predict the linear variation, HOBT5 and HOBT4b bring out the warping of the cross section clearly. The inplane stress variation also illustrates the difference in the predictions of Timoshenko, HOBT4a and the rest, as shown in Fig. 6. 


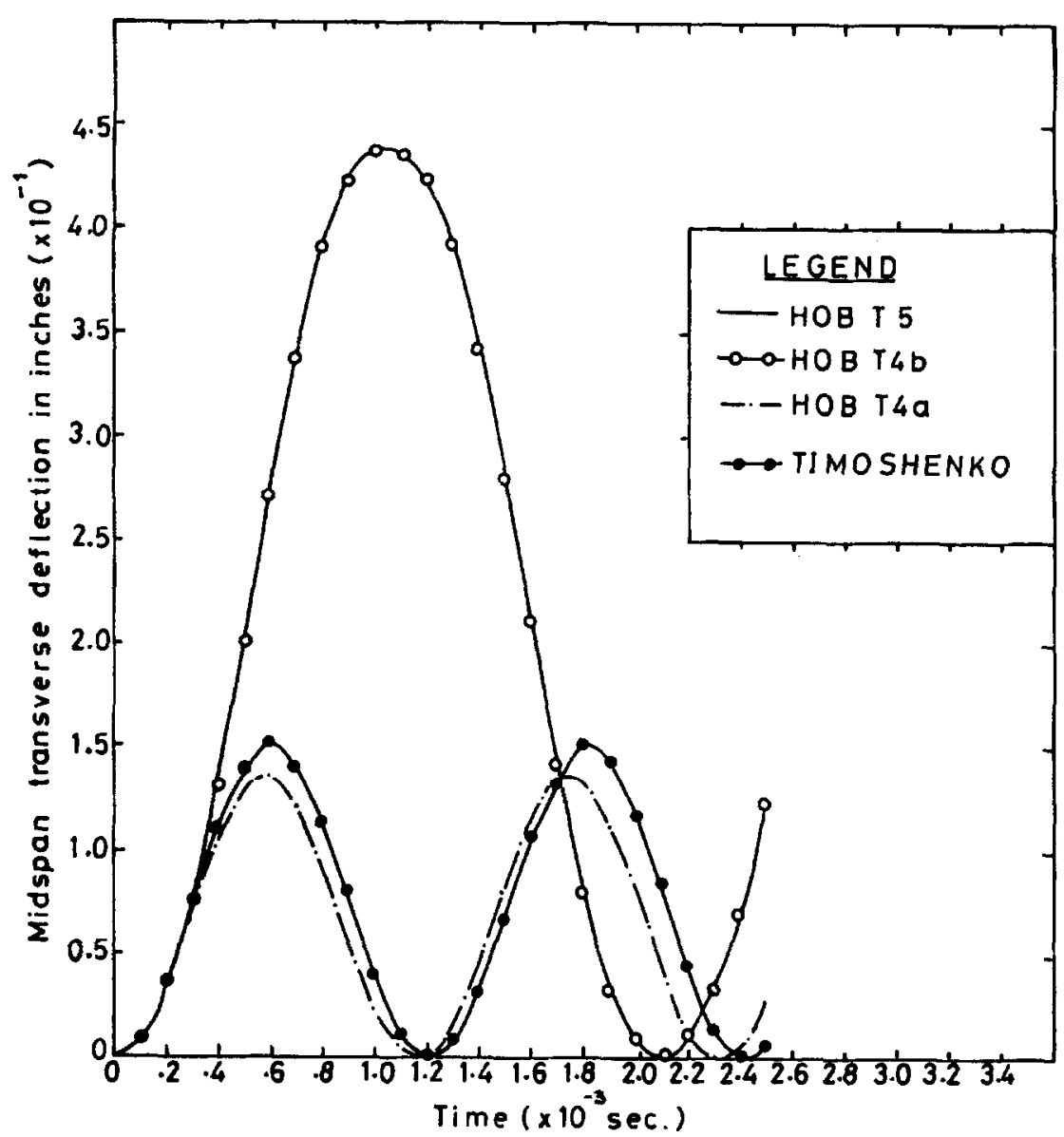

Fig. 1. Variation of midspan deflection with respect to time of symmetric sandwich beam.

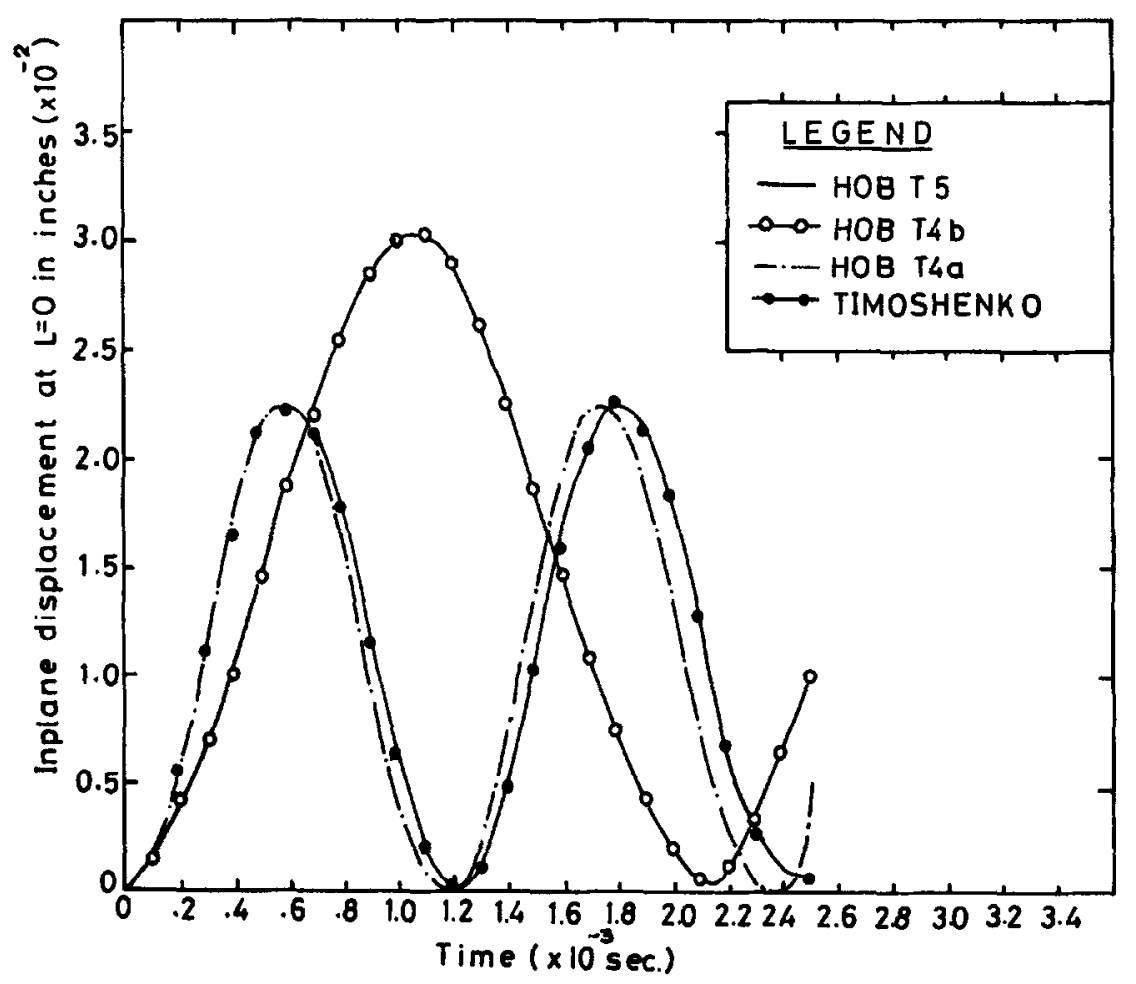

Fig. 2. Variation of inplane displacement with time of symmetric sandwich beam. 


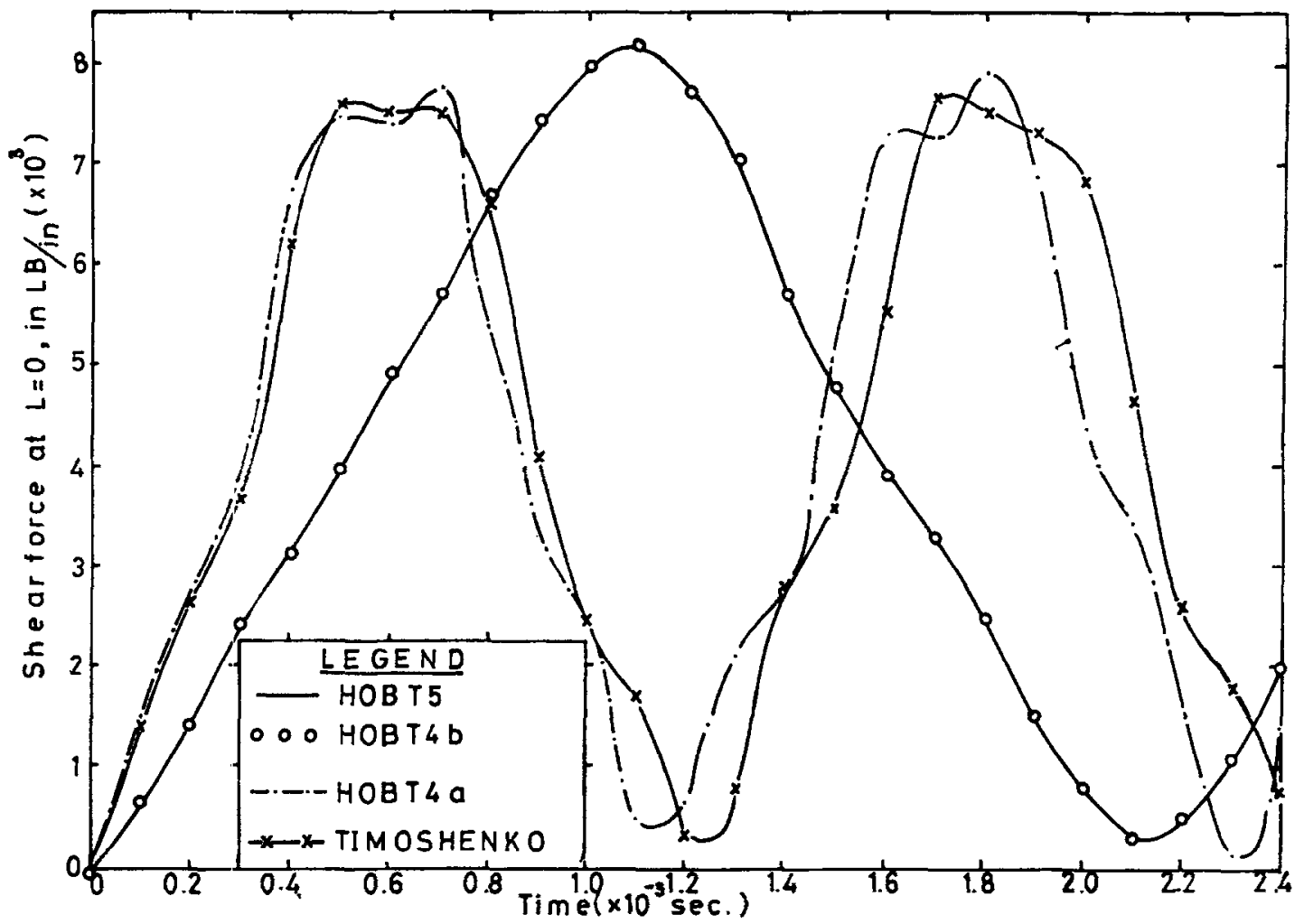

Fig. 3. Shear force variation with time of symmetric sandwich beam.

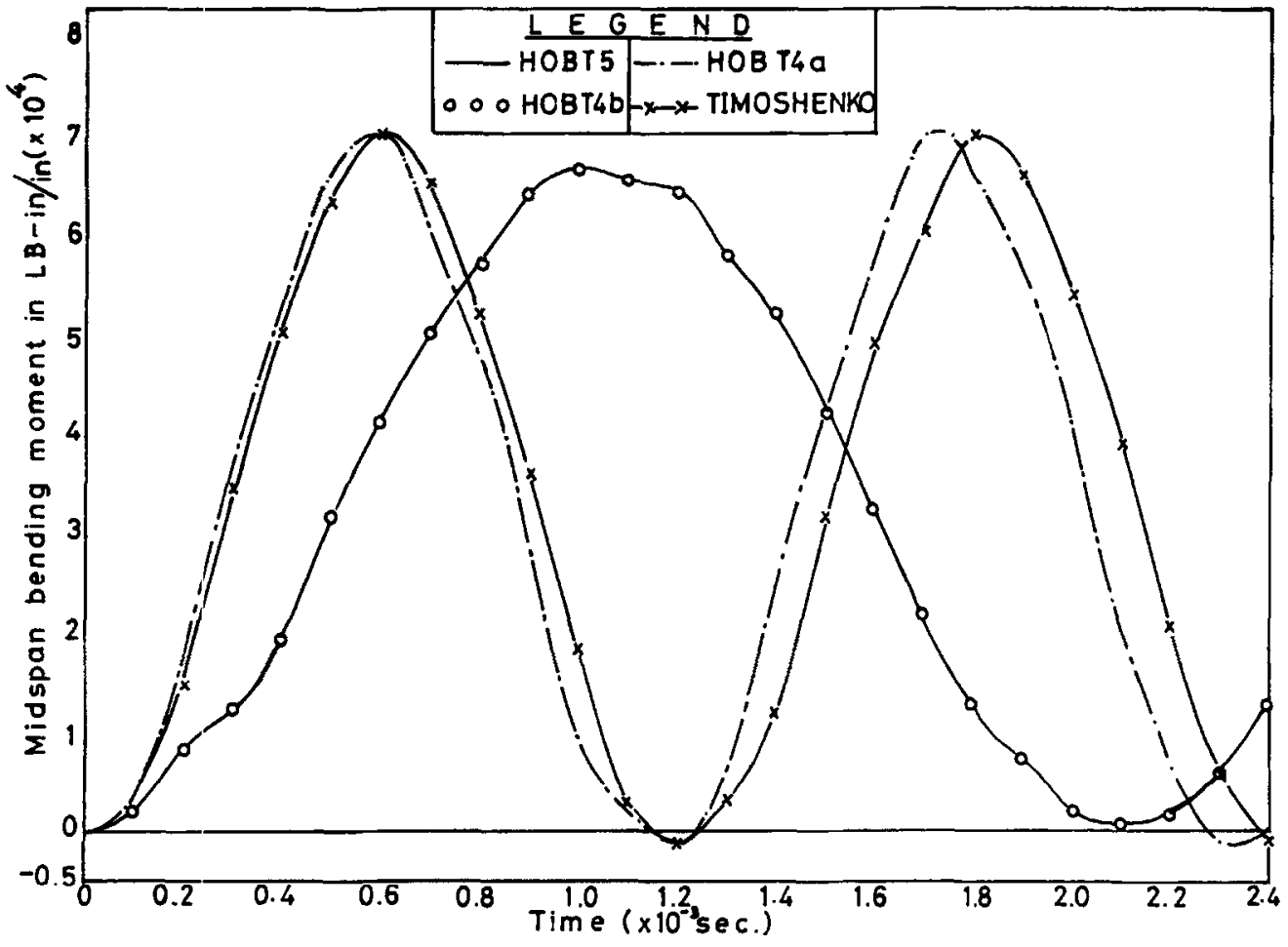

Fig. 4. Bending moment variation with time of symmetric sandwich beam. 


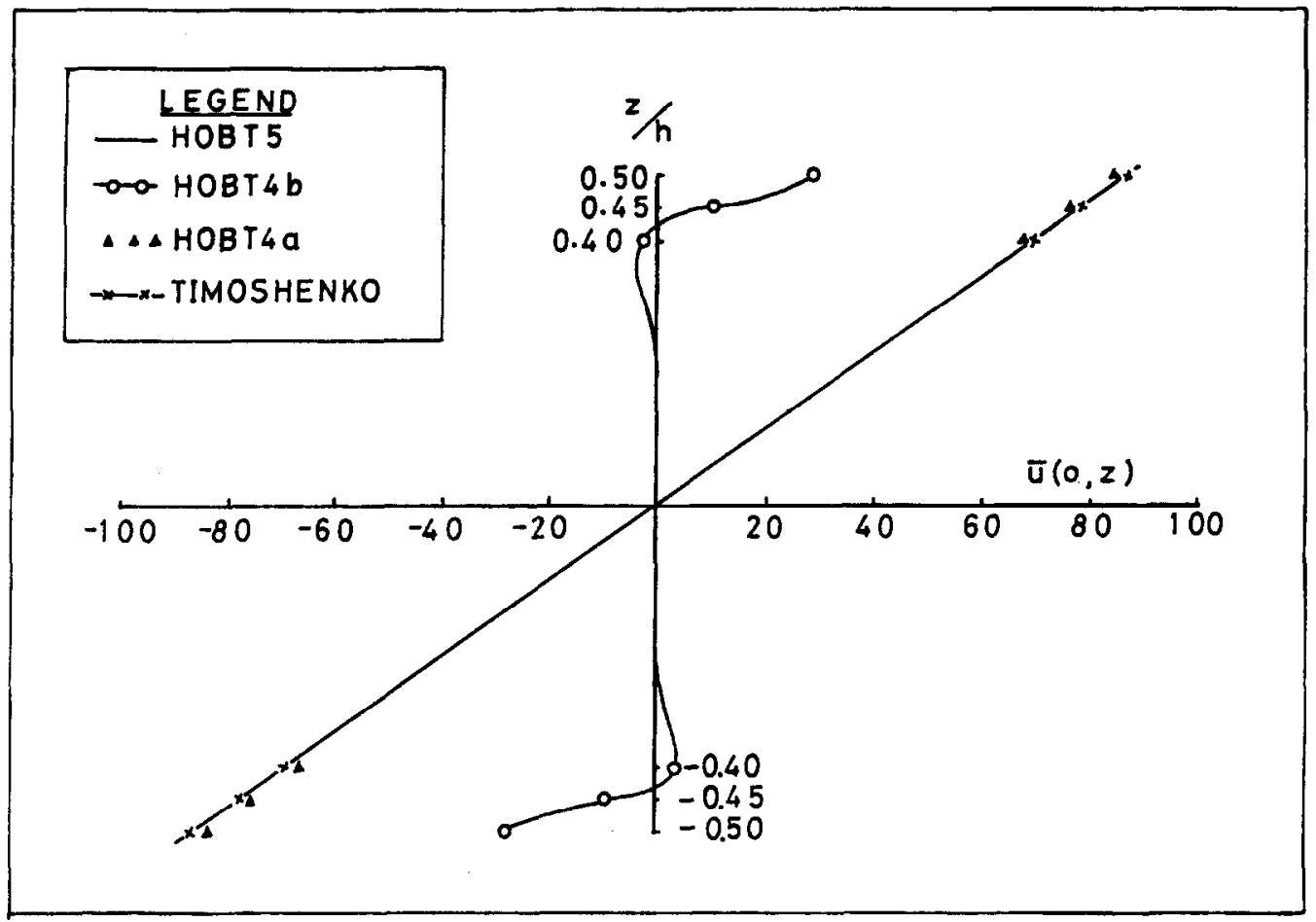

Fig. 5. Inplane displacement distribution of symmetric sandwich beam at $T=0.18 \times 10^{-2} \mathrm{~s}$.

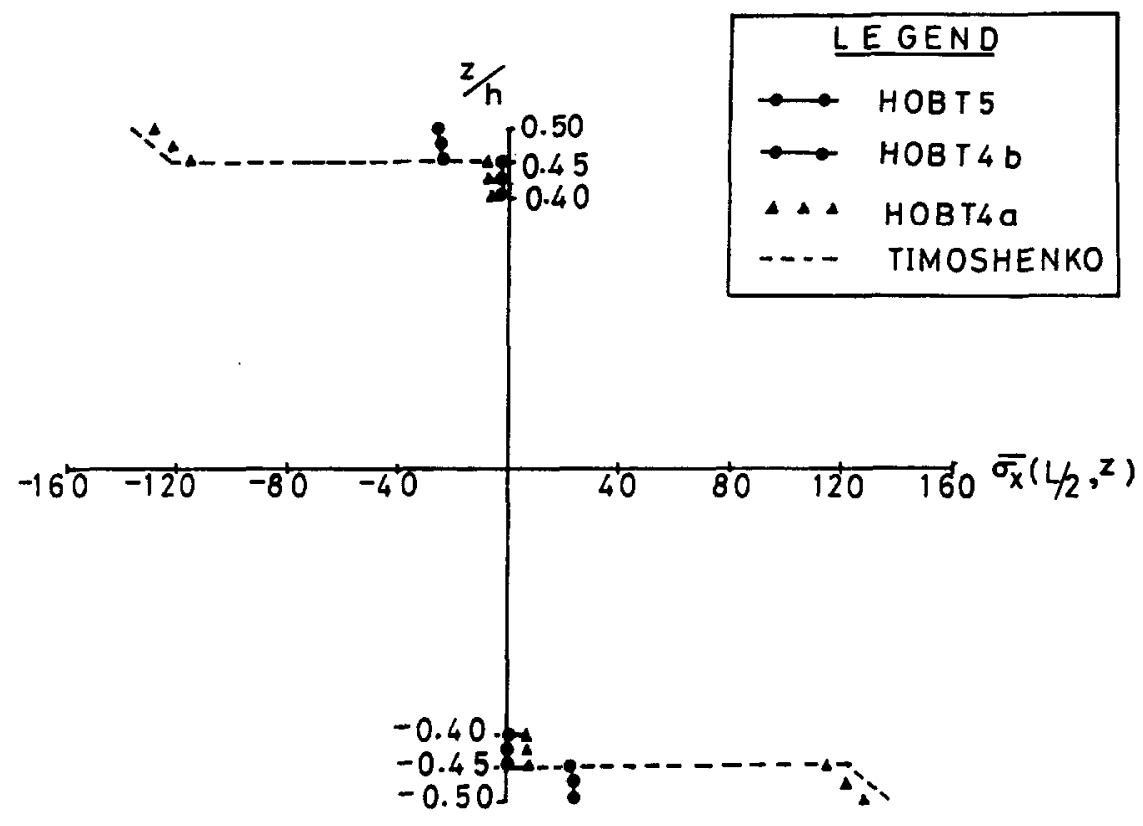

Fig. 6. Inplane stress distribution of symmetric sandwich beam at $T=0.18 \times 10^{-2} \mathrm{~s}$. 


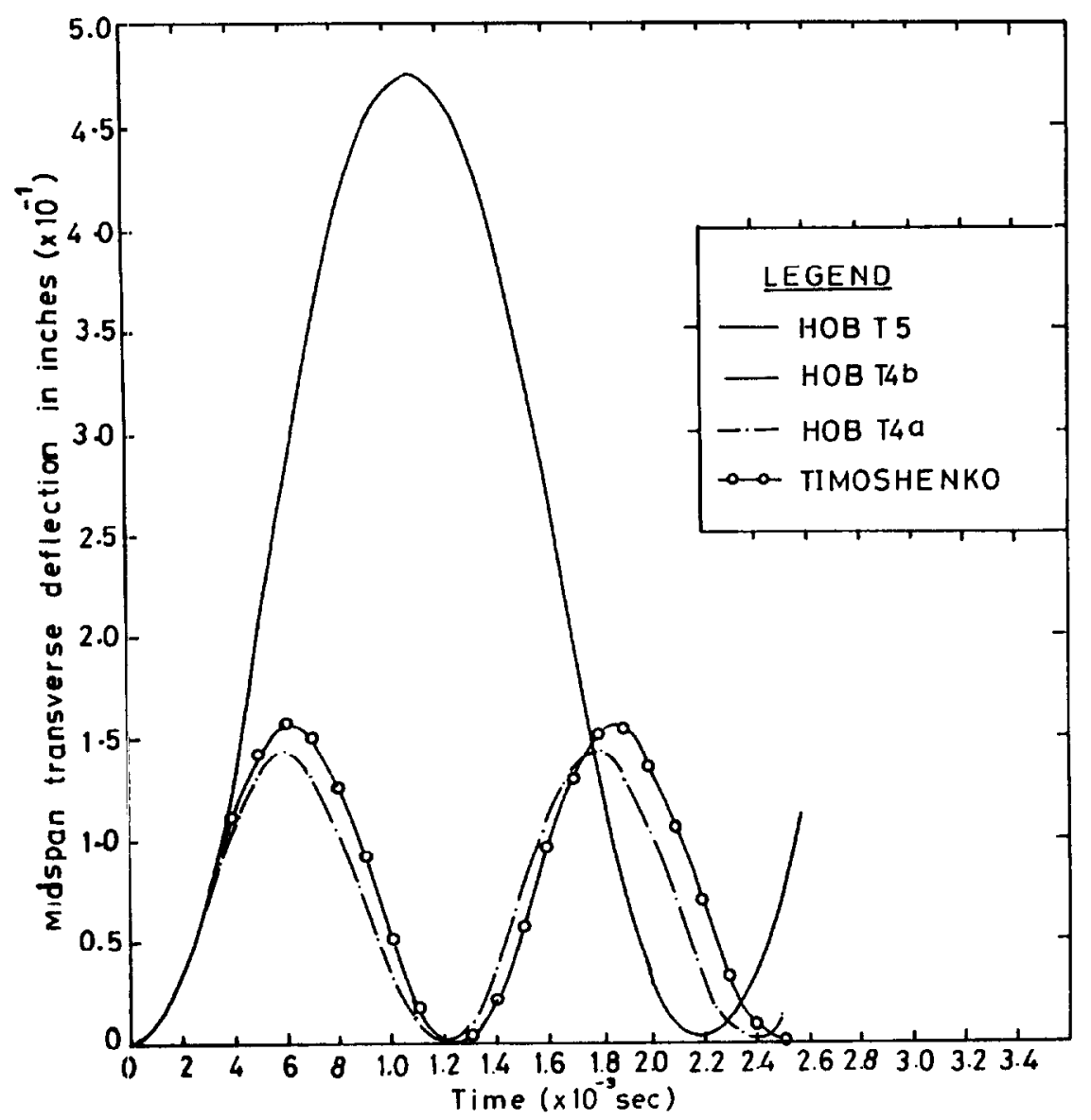

Fig. 7. Midspan transverse response history of unsymmetric sandwich beam.

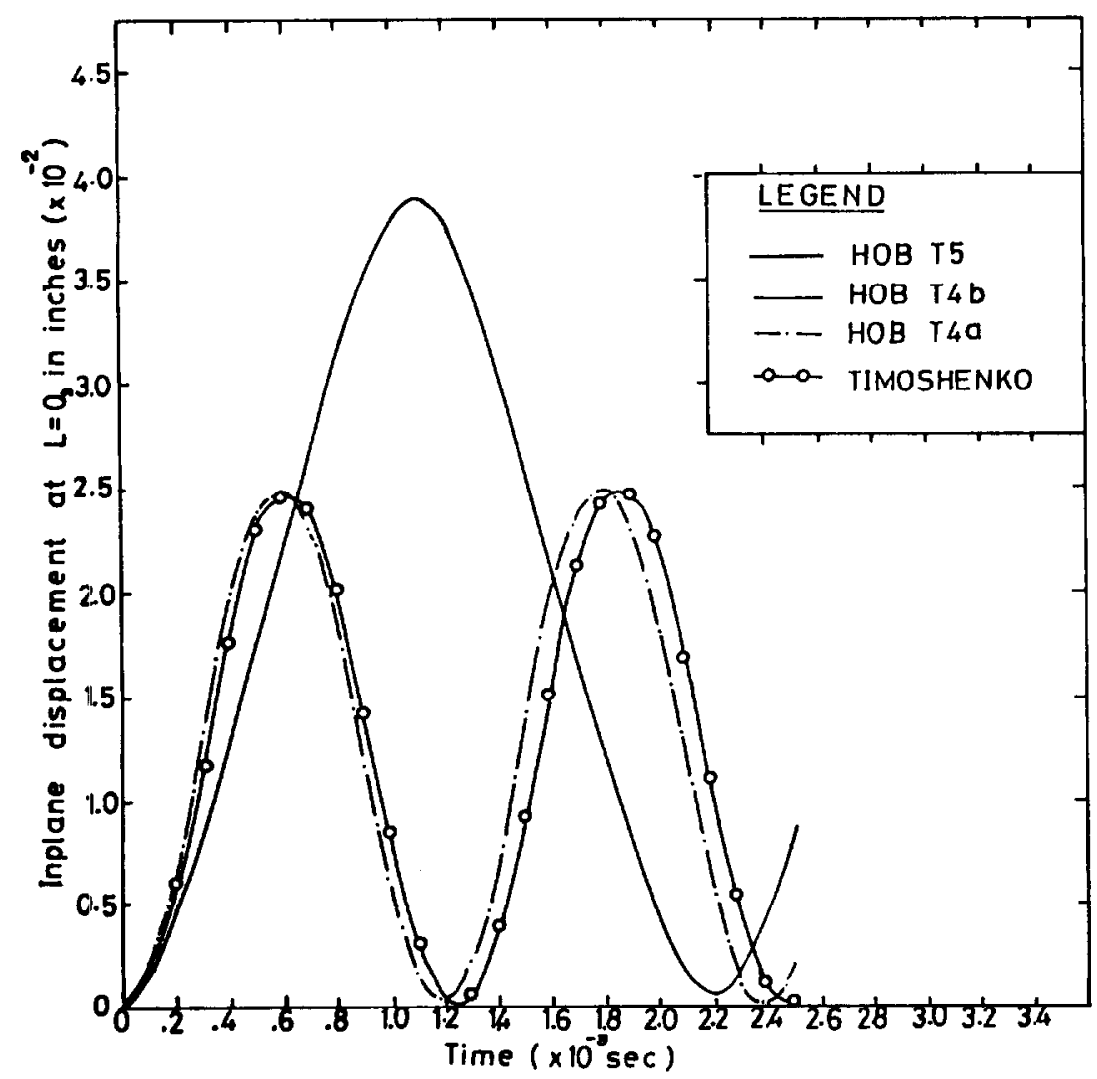

Fig. 8. Inplane displacement history with time of unsymmetric sandwich beam. 


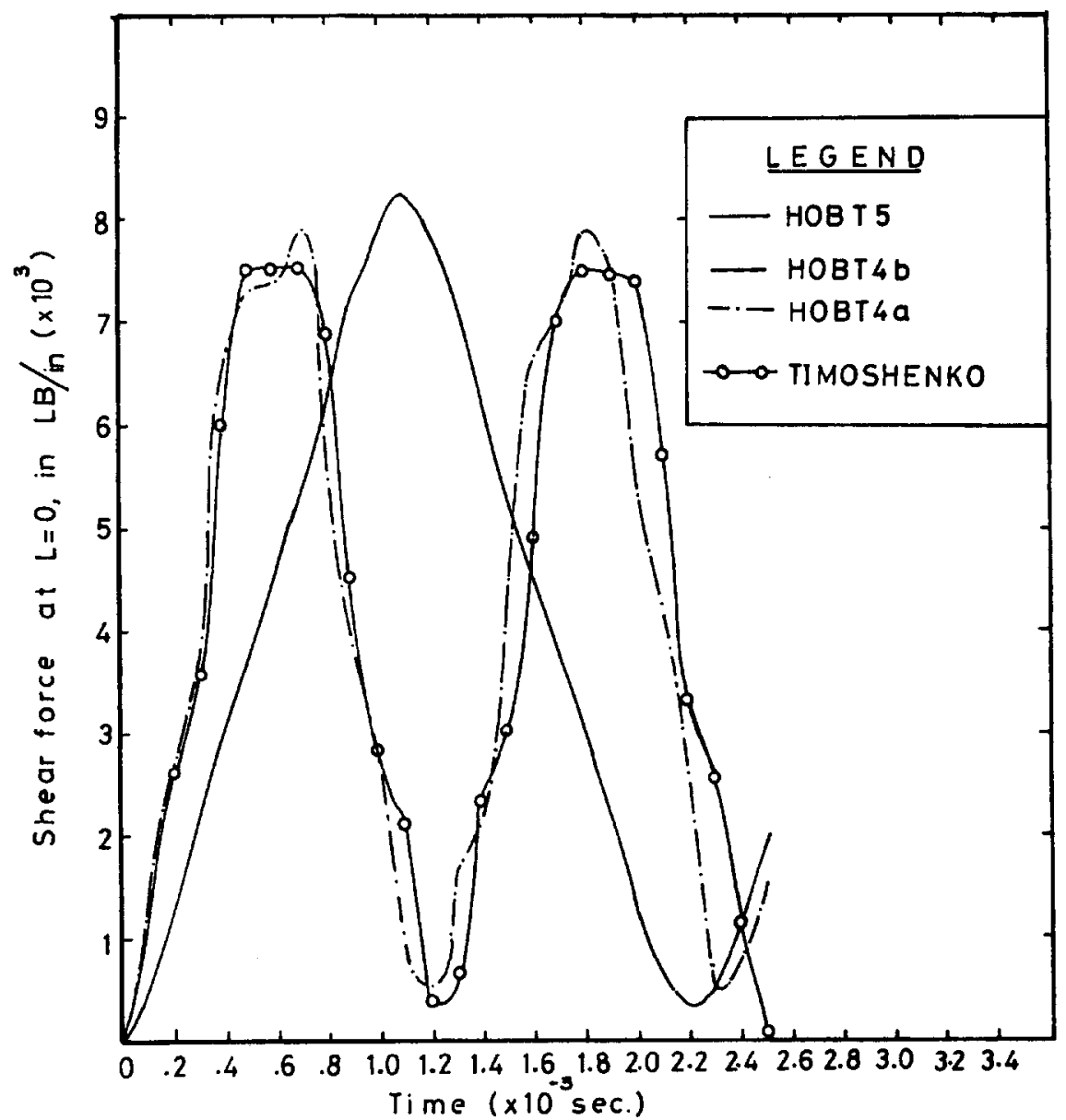

Fig. 9. Shear force variation with time of unsymmetric sandwich beam.

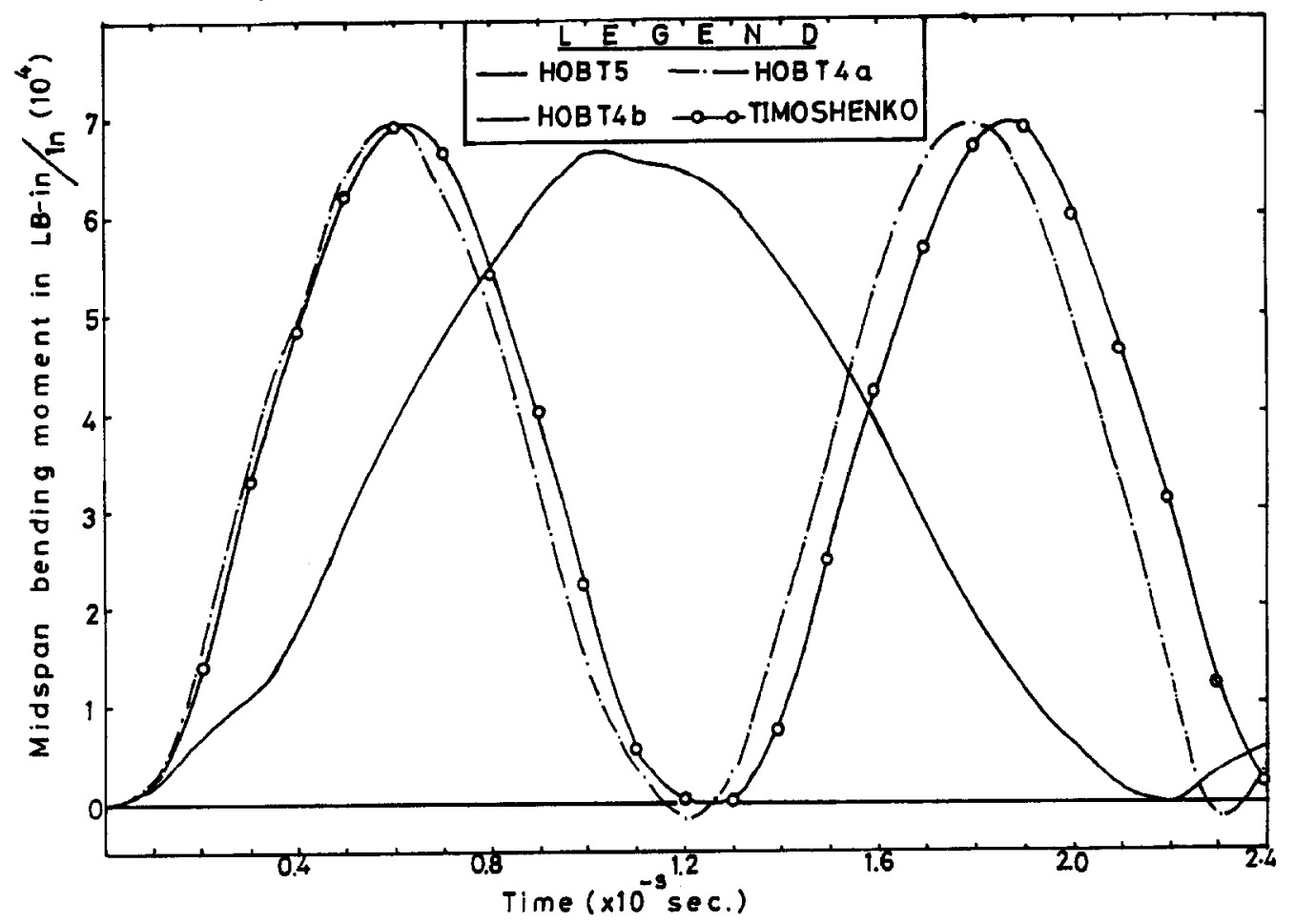

Fig. 10. Bending moment history with time of unsymmetric sandwich beam. 


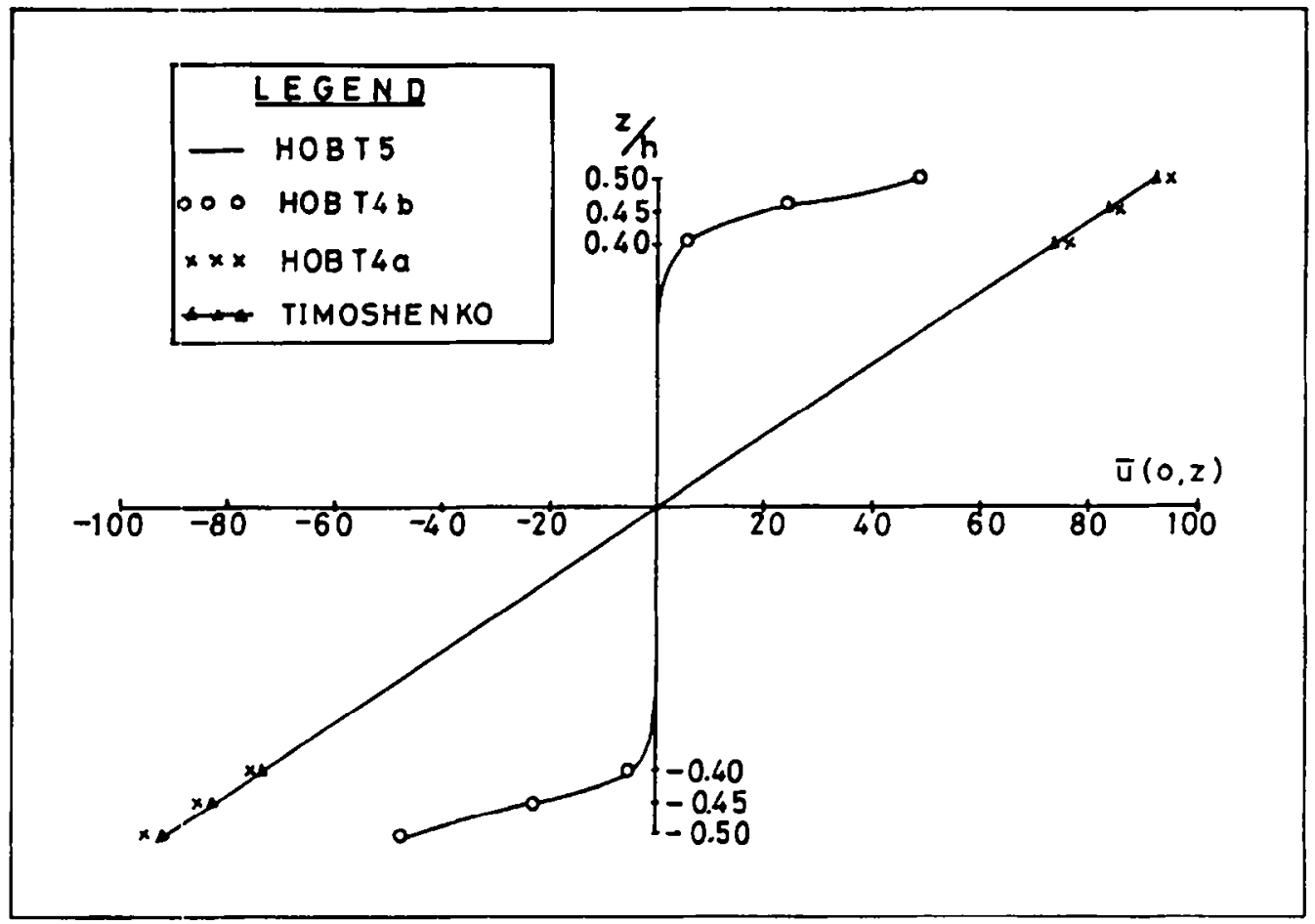

Fig. 11. Distribution of inplane displacement of unsymmetric sandwich beam at $T=0.18 \times 10^{-2} \mathrm{~s}$.

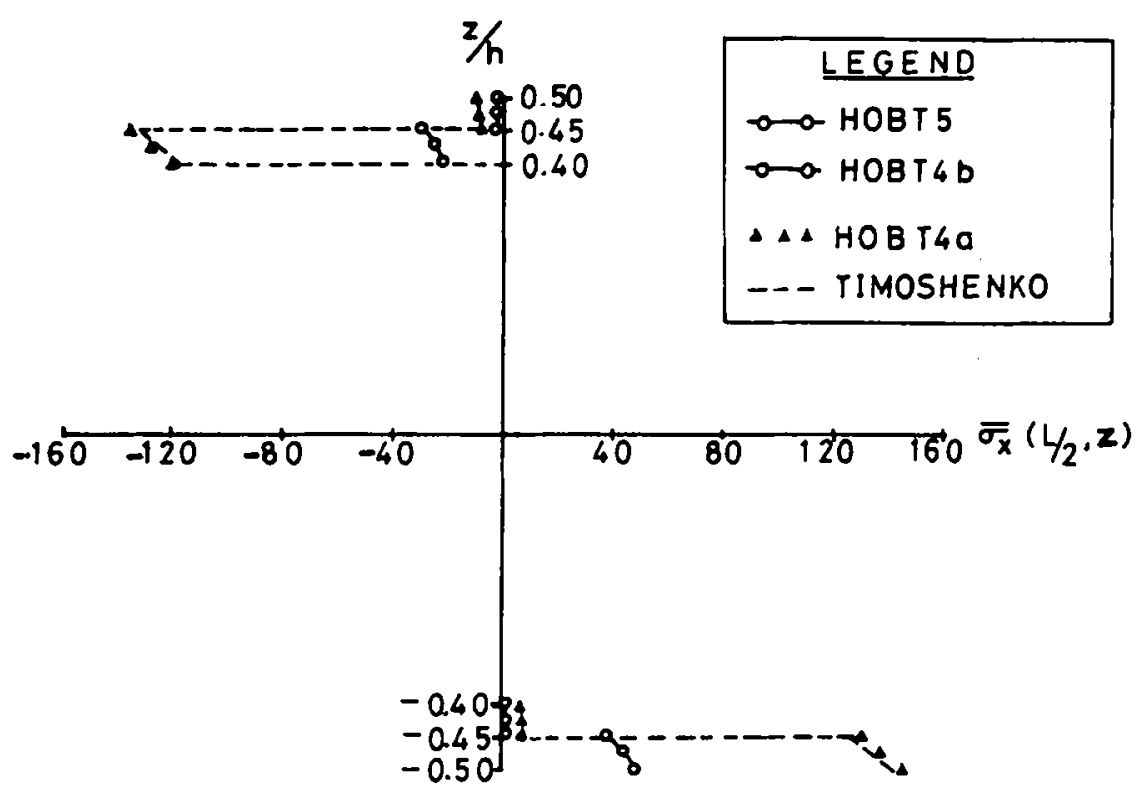

Fig. 12. Distribution of inplane stress of unsymmetric sandwich beam at $T=0.18 \times 10^{-2} \mathrm{~s}$. 


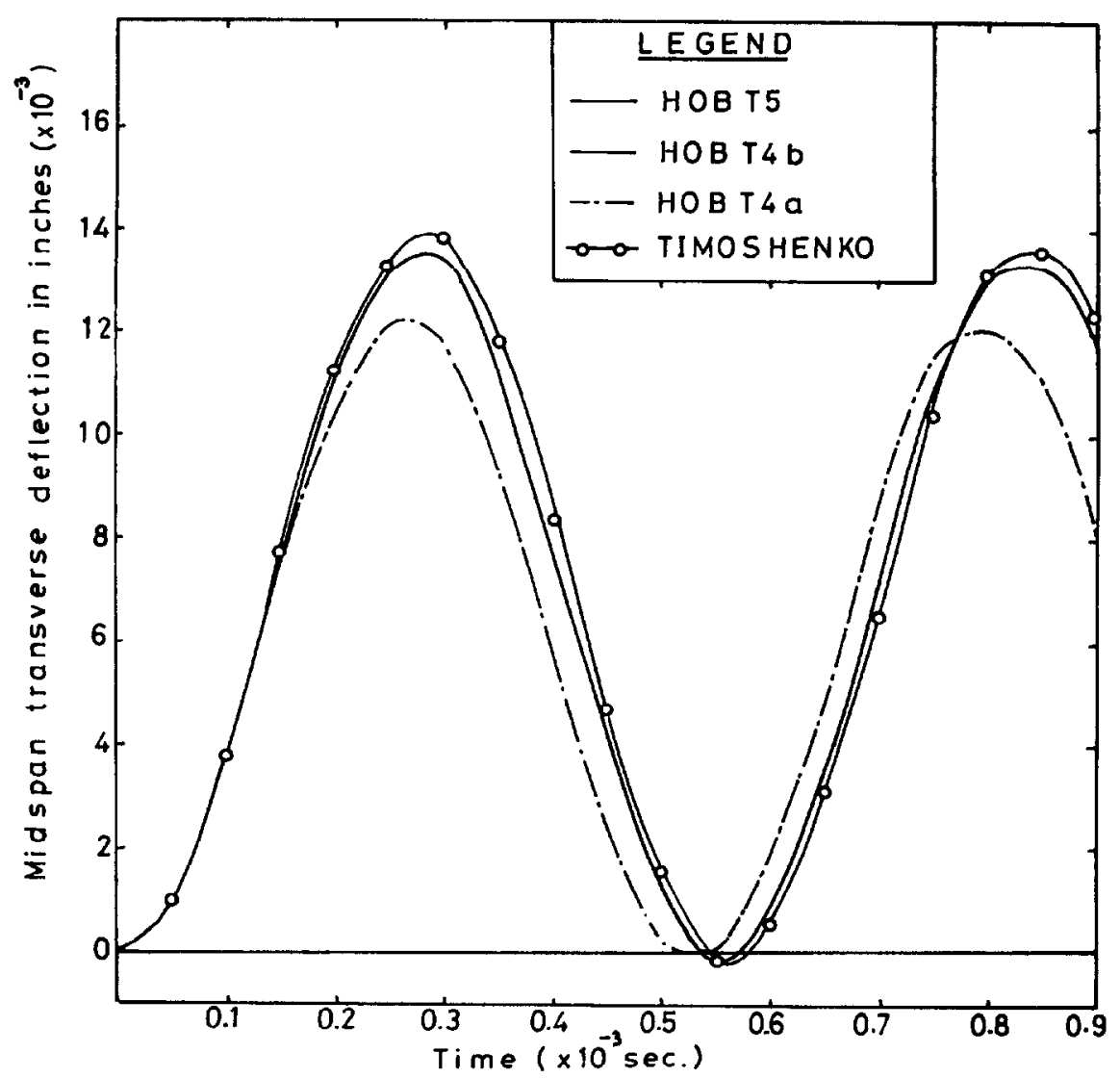

Fig. 13. Transverse deflection history of symmetric composite beam.

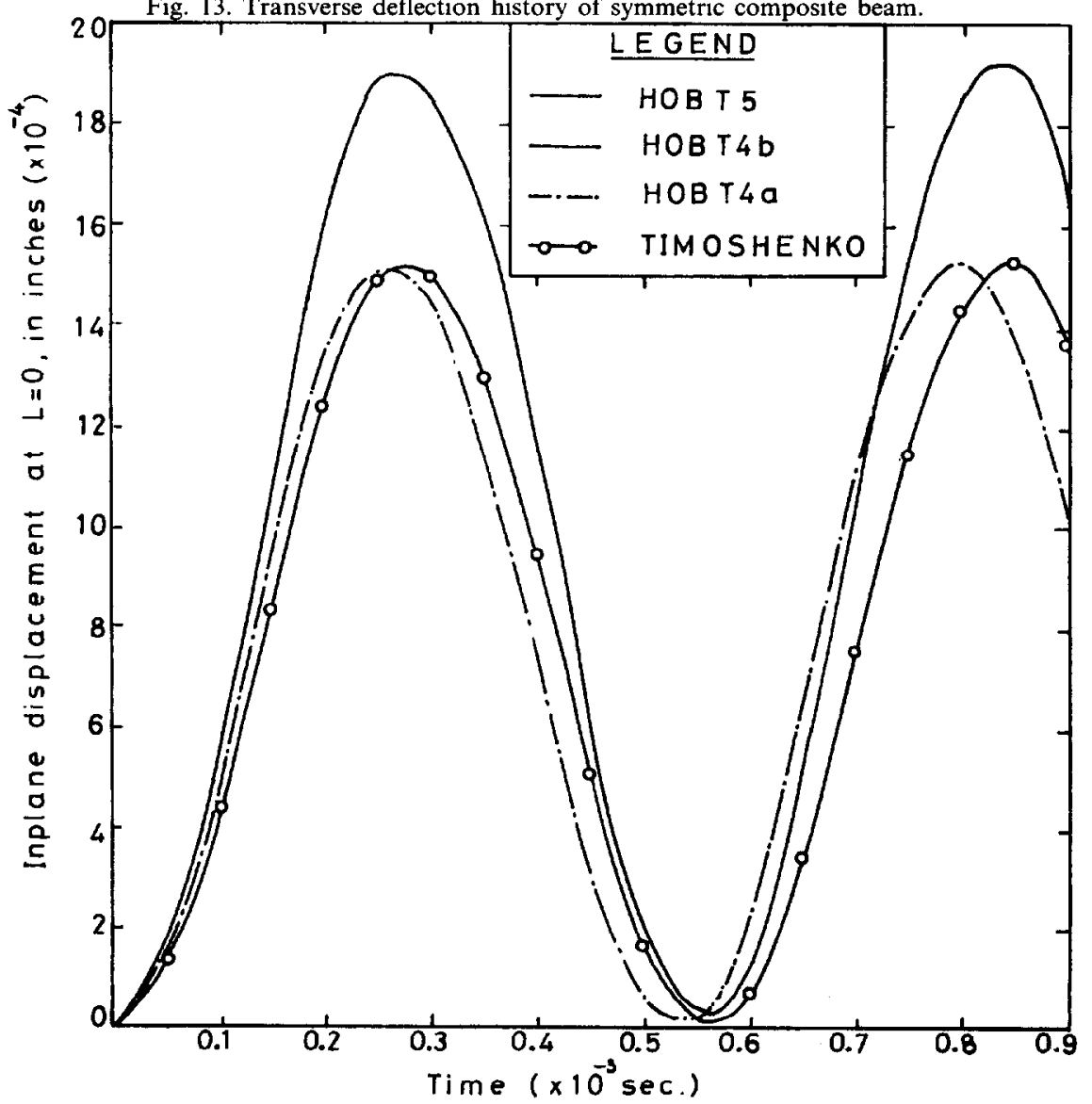

Fig. 14. Inplane displacement history of symmetric composite beam. 


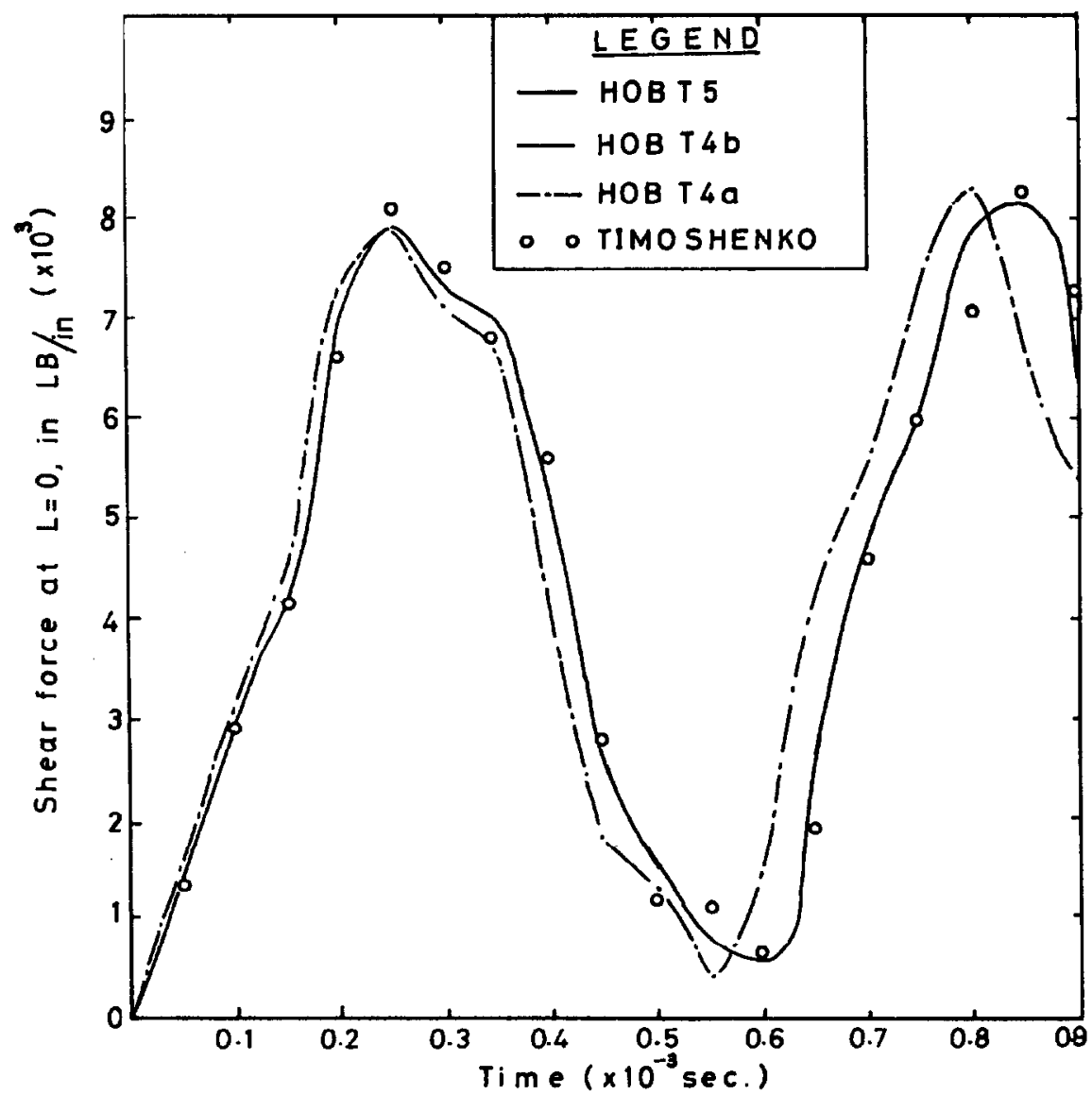

Fig. 15. Shear force history of symmetric composite beam.

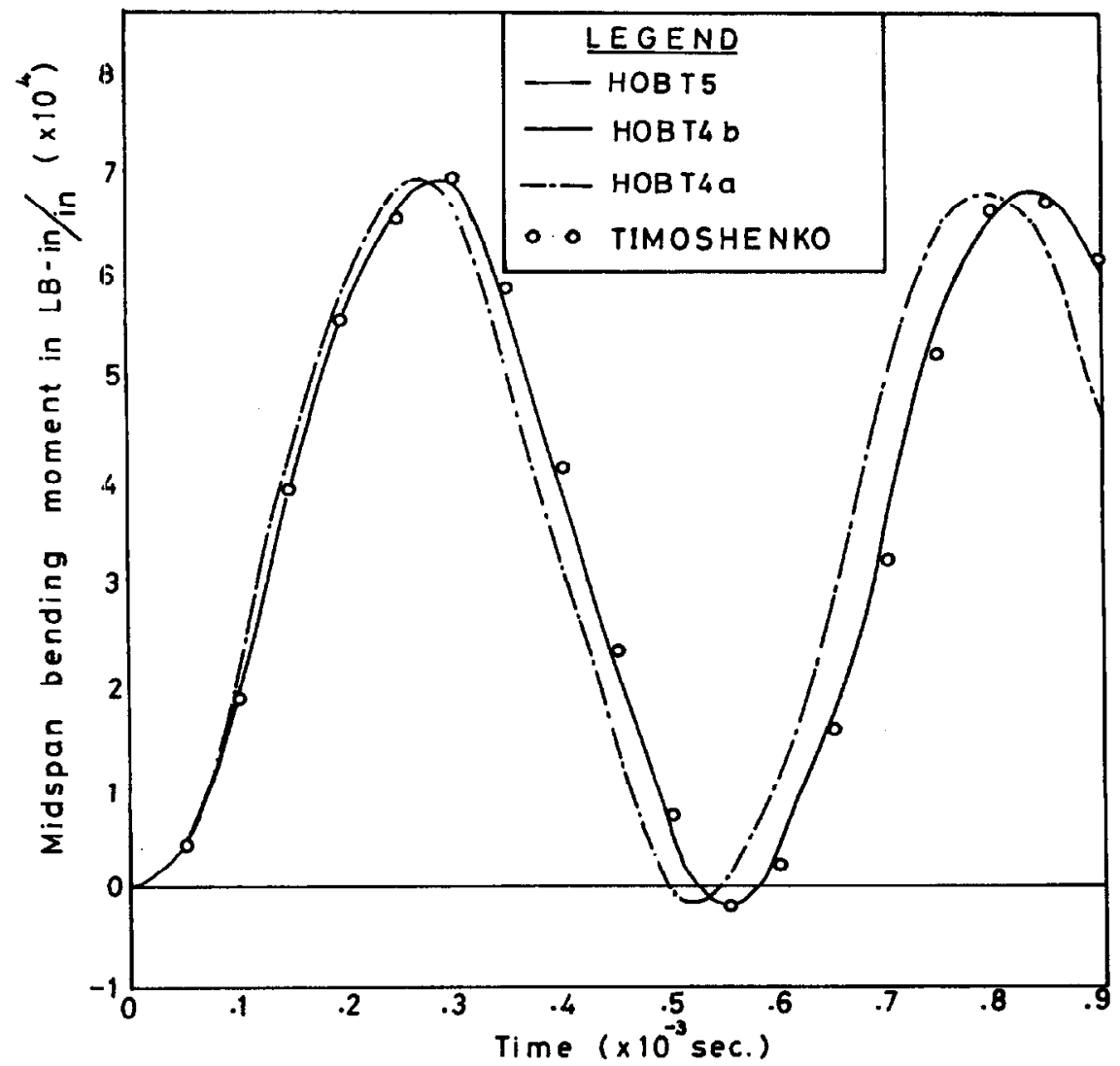

Fig. 16. Bending moment history of symmetric composite beam. 


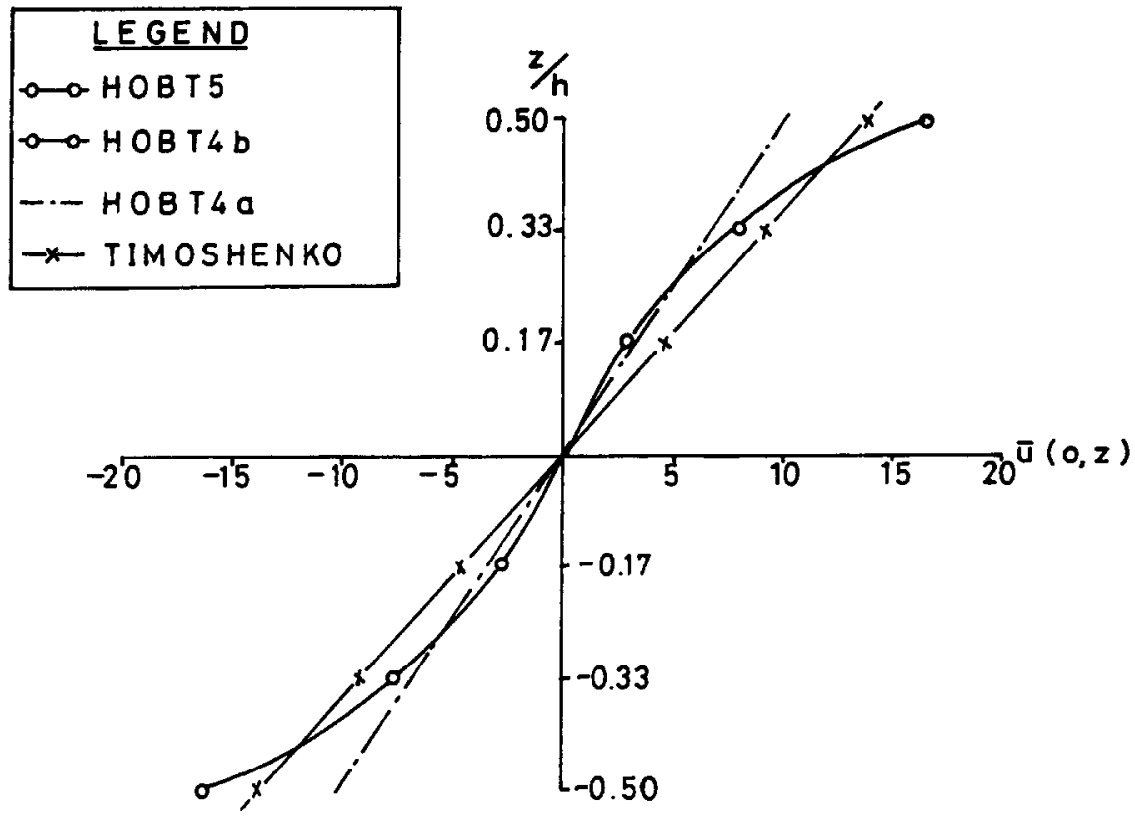

Fig. 17. Distribution of inplane displacement of symmetric composite beam at $T=0.9 \times 10^{-3} \mathrm{~s}$.

\section{Experiment 2}

The same data used in Experiment 1 is considered here, but with an unsymmetric configuration of $0 / 90 /$ core $/ 0 / 90$. The transverse displacement response is shown in Fig. 7. The magnitude and period of the response of HOBT5 and HOBT4b are $3 \times$ and $2 \times$ that of Timoshenko; HOBT4a is stiffer than first-order theory. The variation of inplane displacement, shear force and bending moment are given in Figs 8-10. The magnitude of inplane displacement and the period of shear and bending moment of higher order models are nearly double those computed by first-order model and HOBT4a.

Timoshenko and HOBT4a predict only a linear

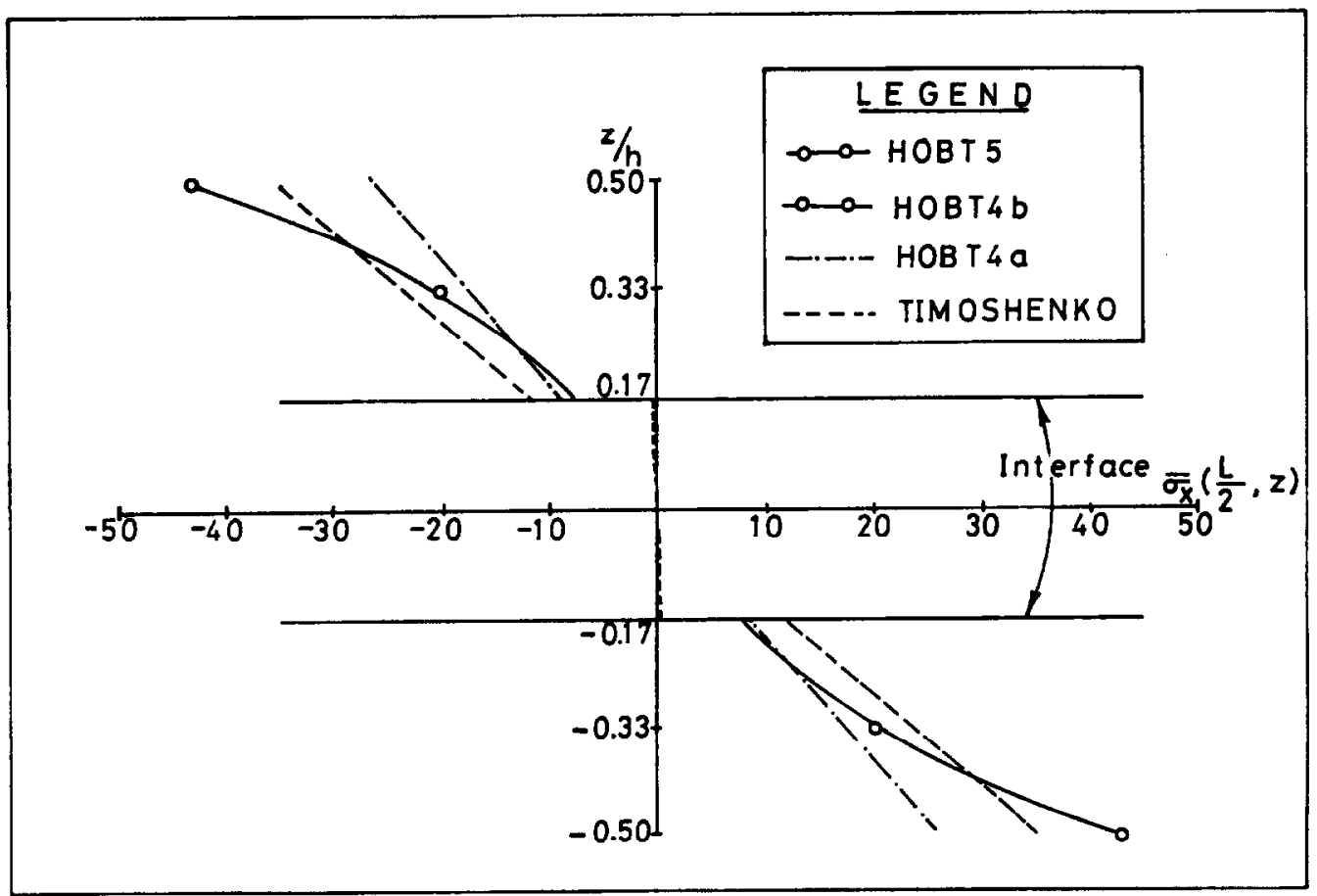

Fig. 18. Inplane stress distribution of symmetric composite beam at $T=0.9 \times 10^{-3} \mathrm{~s}$. 


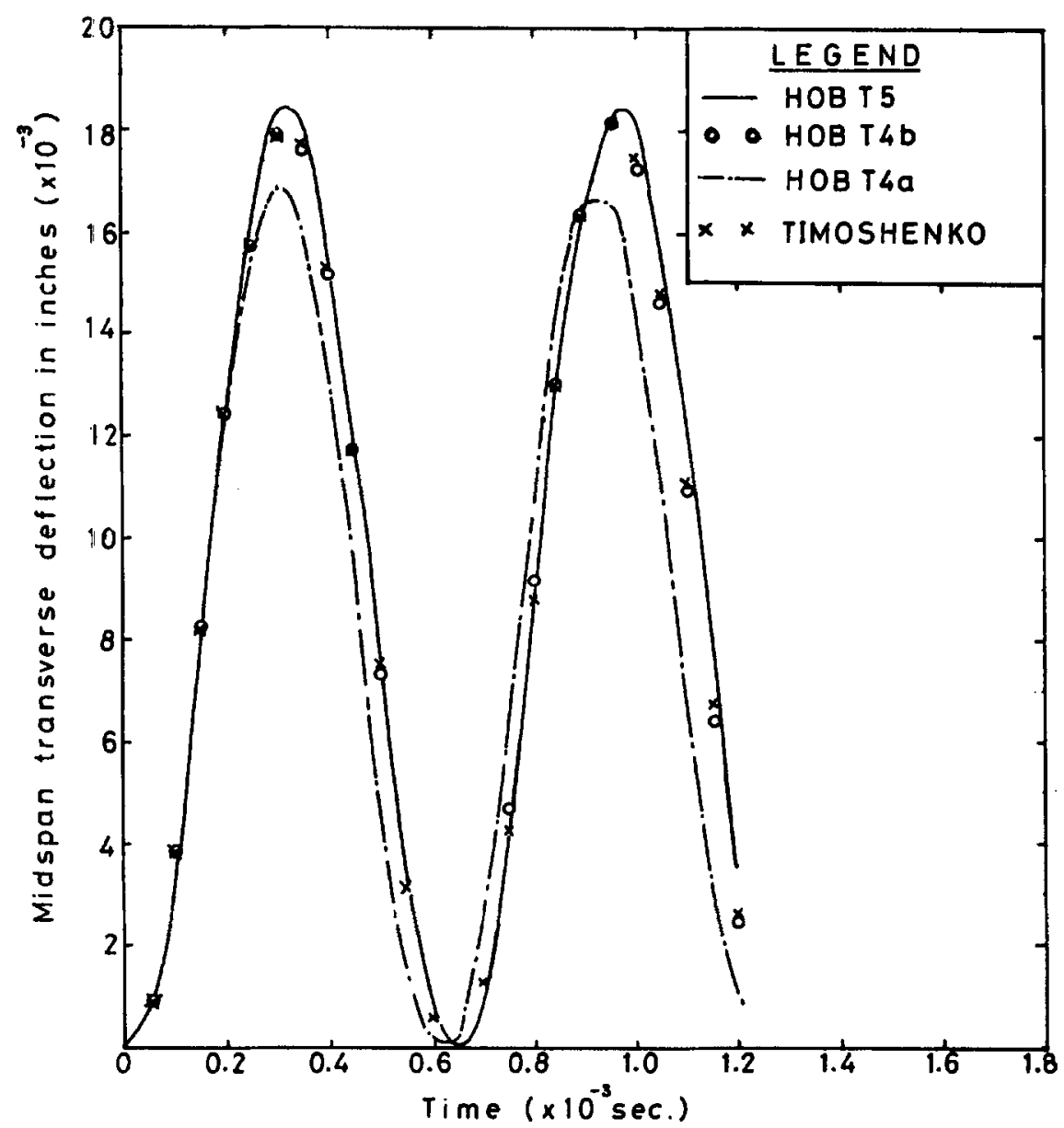

Fig. 19. Transverse deflection history of unsymmetric composite beam.

inplane displacement while higher-order models show the nonlinear variation in Fig. 11. Variation of $\bar{\sigma}_{x}$ is plotted in Fig. 12. The higher-order models compute stresses that are lesser than those predicted by the other two, mainly due to the fact that inplane displacement by HOBT5 and HOBT4b at $t=0.18 \times 10^{-2} \mathrm{~s}$, is much less than those predicted by HOBT $4 a$ and first-order theory, as can be seen in Fig. 8.

\section{Experiment 3}

Next, a symmetric composite construction of $0 / 0 / 90 / 90 / 0 / 0$ combination with the following properties is considered [32].

Data 2

$$
\begin{aligned}
E_{x} & =0.7620 \times 10^{8} \mathrm{psi} \\
E_{z} & =0.3048 \times 10^{7} \mathrm{psi} \\
G_{x z} & =0.1524 \times 10^{7} \mathrm{psi} \\
\rho & =0.7257 \times 10^{-4} \mathrm{lb} \mathrm{s}^{2} \mathrm{in}^{-4} \\
t_{\text {layer }} & =1 \mathrm{in} .
\end{aligned}
$$

The transverse displacement by Timoshenko is the highest in this case followed by HOBT5 and HOBT4b, as shown in Fig. 13; HOBT4a is again the stiffest. In the case of inplane displacements, HOBT5 and IIOBT4b are the highest, followed by Timoshenko and HOBT4a as in Fig. 14. This is due to the presence of various higher-order terms in the displacement function of $u$. From Figs 15 and 16 , it can be observed that all higher-order models are marginally lesser than Timoshenko in their predictions of shear force and bending moment.

The cross sectional warping clearly brought out by higher-order models is presented in Fig. 17. Similarly, the nonlinear variation of inplane stress by higherorder models is shown in Fig. 18.

\section{Experiment 4}

The unsymmetric configuration of $0 / 90 / 0 / 90 / 0 / 90$ with the properties given by Data 2 , is considered in this case for time history response evaluation of the beam. From Fig. 19, it can be observed that HOBT5 predicts a transverse displacement response, which is higher than those of HOBT4b and Timoshenko (which are quite close in this case), while HOBT4a computes the stiffest results of all. The inplane displacement history, as in Fig. 20, presents a different picture. HOBTS computes the highest, followed by HOBT4b, HOBT4a and Timoshenko in that order. In the case of shear force, HOBT4b and 


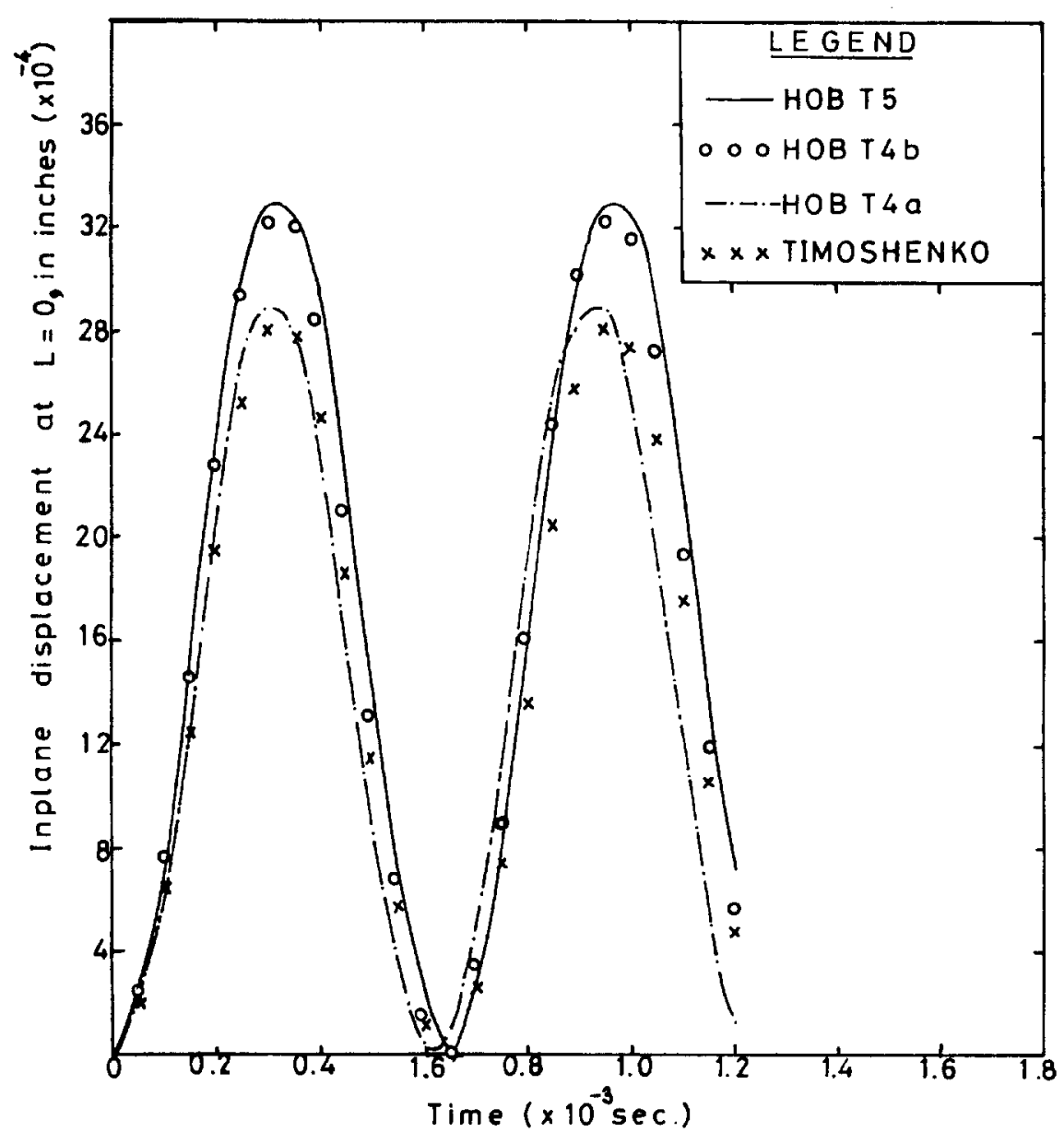

Fig. 20. Inplane displacement history of unsymmetric composite beam.

Timoshenko are much closer to HOBT5 as in Fig. 21, while HOBT4a predicts slightly higher peak values with lesser period. The bending moment by Timoshenko, HOBT4a and HOBT4b closely follow the HOBT5 moment with HOBT4a again having lesser period compared to others, as plotted in Fig. 22.

The variation of $\overline{\mathbf{u}}$ and $\overline{\boldsymbol{\sigma}}_{x}$ are plotted in Figs 23 and 24 , which clearly brings out the nonlinear inplane displacement and inplane stress variation due to higher-order models compared to the linear predictions by HOBT $4 \mathrm{a}$ and Timoshenko.

\section{CONCLUSIONS}

In our study, three refined higher-order, shear correction coefficient free models have been analysed by employing them for transient dynamic analysis of sandwich and composite beams. From the experiments conducted, it becomes apparent that the very stiff performance of HOBT4a renders it almost unusable.

The higher order models (HOBT5 and HOBT4b) predict responses which are quite high compared to Timoshenko, for both symmetric and unsymmetric sandwich constructions. The warping of cross section and nonlinear inplane distributions is vividly brought out by these higher-order models. Another interesting feature in the case of sandwiches, is that both HOBT5 and HOBT4b predict identical results.

In the case of composites, the order of difference between the higher-order and the first-order models is less compared to sandwiches. Timoshenko predicts slightly higher values in comparison with these higher-order models for symmetric composites, except for inplane displacements. For the unsymmetric composites, HOBT5 yields higher inplane and transverse displacements than those given by the rest. For both the symmetric and unsymmetric cases, the warping of the cross section and the nonlinear inplane stress distribution is brought out well by higher order models.

For sandwiches and symmetric composites, as both HOBT5 and HOBT4b are identically effective, and for unsymmetric composites as HOBT5 is better than HOBT4b, HOBT5 can well be employed as an efficient higher-order refined model for transient dynamic analysis of sandwich and composite constructions of beams. 

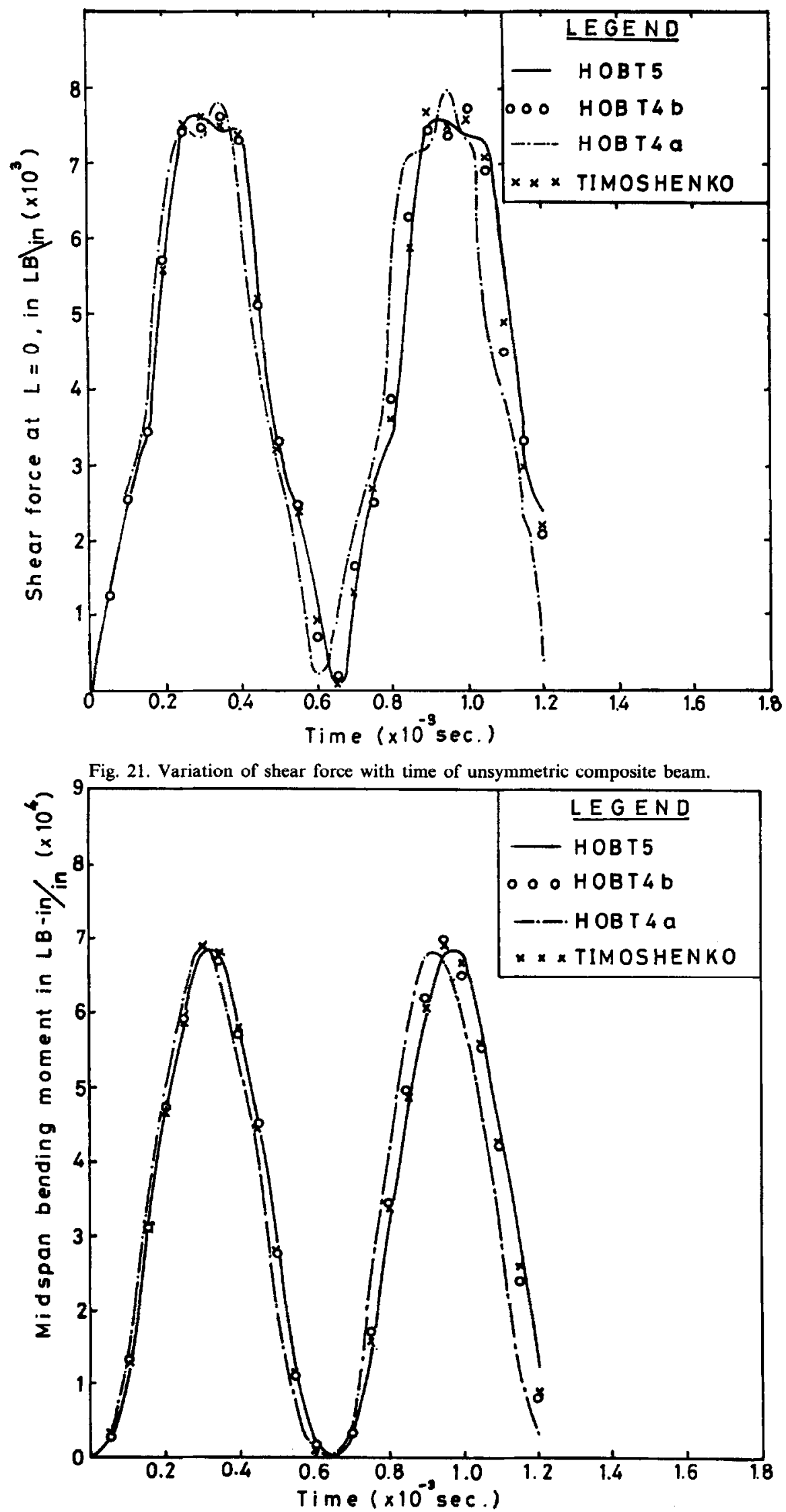

Fig. 22. Variation of bending moment with time of unsymmetric composite beam. 


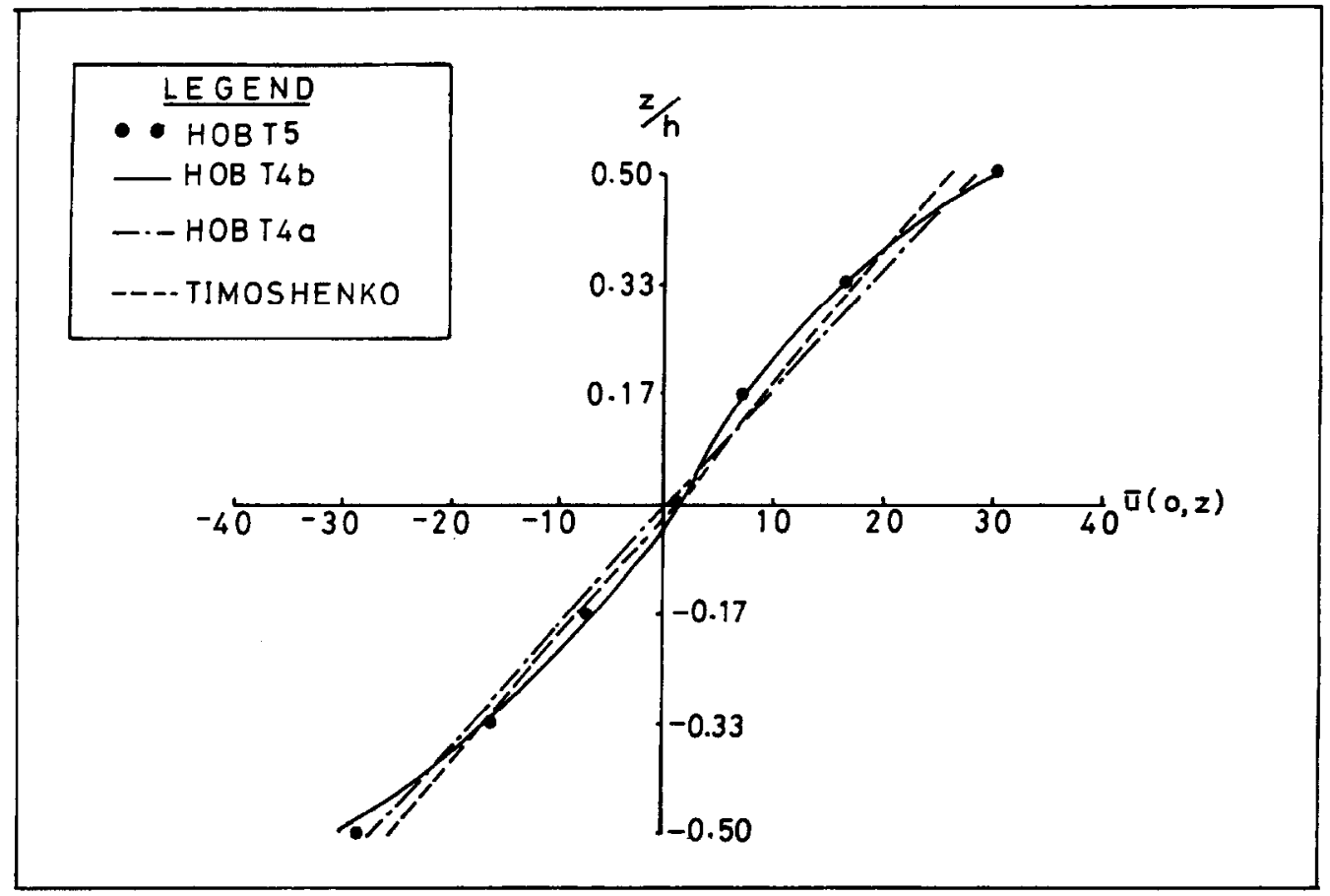

Fig. 23. Inplane displacement distribution of unsymmetric composite beam at $T=0.9 \times 10^{-3} \mathrm{~s}$.

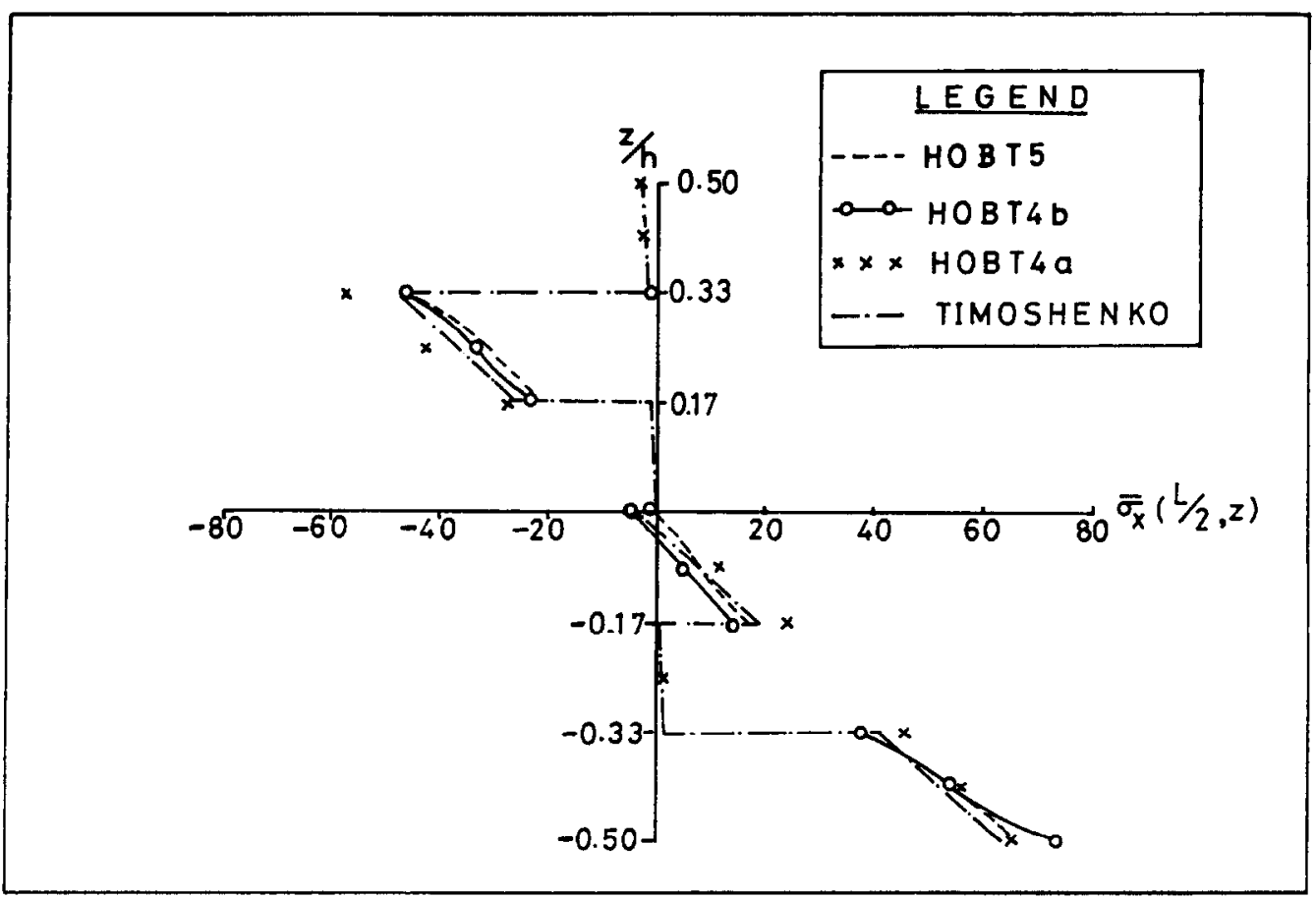

Fig. 24. Distribution of inplane stress of unsymmetric composite beam at $T=0.9 \times 10^{-3} \mathrm{~s}$.

\section{REFERENCES}

1. Wu, R. W. H. and Witmer, E. A., Finite element analysis of large elastic-plastic transient deformations of simple structures. AIAA Journal, 1971, 9, 1719-1724.

2. Toridis, T. G. and Khozeimeh, K., Inelastic response of frames to dynamic loads. Journal of the Structural Division of the ASCE $, 1971,97,847-863$.
3. Toridis, T. G. and Khozeimeh, K., Computer analysis of rigid frames. Computers and Structures, 1971, 1, 1.93-221.

4. Mondkar, D. P. and Powell, G. H., Finite element analysis of nonlinear static and dynamic response. International Journal of Numerical Methods in Engineering, 1977, 11, 499-520.

5. Hilmy, S. I. and Abel, J. F., Material and geometric 
nonlinear dynamic analysis of steel frames using computer graphics. Computers and Structures, 1985, 21, 825-840.

6. Kam, T. Y. and Lin, S. C., Nonlinear dynamic analysis of inelastic steel plane frames. Computers and Structures, 1988, 28, 535-542.

7. Timoshenko, S. P., On the correction for shear in differential equations for transverse vibrations of prismatic bars. Philosophical Magazine, Series 6, 1921, 41, 744-746.

8. McCallay, R., Rotary inertia correction for mass matrices. Report no. DIG/SA, GEC, New York, 63-73, 1963.

9. Archer, J., Consistent matrix formulations for structural analysis using finite element techniques. AIAA Journal, 1965, 3, 1910-1928.

10. Kapur, K., Vitirations of a Timoshenko beam using finite element approach. Journal of the Acoustic Society of America, 196i6, 40, 1058-1063.

11. Carniege, W., Thomas, J. and Dokumaci, E., An improved method of matrix displacement analysis in vibration problems. Aeronautical Quarterly, 1969, 20, 321-332.

12. Davis, R., Henshell, R. D. and Warburton, G. B., A Timoshenko beam element. Journal of Sound and Vibration, 1972, 22, 475-487.

13. Nickel, R. and Secor, G., Convergence of consistently derived Timoshenko beam finite elements. International Journal of Numerical Methods in Engineering, 1972, 5, 243-253.

14. Thomas, D. L., Wilson, J. M. and Wilson, R. R., Timoshenko beam finite elements. Journal of Sound and Vibration, 1973, 31, 315-330.

15. Thomas, J. and Abbas, B. A. H., Finite element model for dynamic analysis of Timoshenko beams. Journal of Sound and Vibration, 1975, 41, 291-299.

16. Kant, T. and Marur, S. R., A comparative study of $\mathrm{C}^{0}$ and $C^{\prime}$ elements for linear and nonlinear transient dynamics of building frames. Computers and Structures, $1991,40,659-678$.

17. Stephen, N. G. and Levinson, M., A second-order beam theory. Journal of Sound and Vibration, 1979, 67, 293-305.

18. Heyliger, P. R. and Reddy, J. N., A higher-order beam finite element for bending and vibration problems. Journal of Sound and Vibration, 1988, 126, 309-326.

19. Soldatos, K. P. and Elishakoff, I., A transverse shear and normal deformable orthotropic beam theory. Journal of Sound and Vibration, 1992, 154, 528-533.

20. Levinson, M., A new rectangular beam theory. Journal of Sound and Vibration, 1981, 74, 81-87.

21. Rychter, Z., On the accuracy of a beam theory. Mechanical Research Communications, 1987, 14, 99105.

22. Bickford, W. B., A consistent higher-order beam theory. Developments in Theoretical and Applied Mechanics, 1982, 11, 137-142.

23. Reddy, J. N., Energy and Variational Methods in Applied Mechanics. Wiley, New York, 1984.

24. Kant, T. and Gupta, A., A finite element model for a higher-order shear deformable beam theory. Journal of Sound and Vibration, 1988, 125, 193-202.

25. Kant, T. and Manjunath, B. S., Refined theories for composite and sandwich beams with $\mathbf{C}^{0}$ finite elements. Computers and Structures, 1989, 33, 755-764.

26. Kant, T. and Manjunath, B. S., Higher-order theories for symmetric and unsymmetric fibre reinforced composite beams with $\mathrm{C}^{0}$ finite elements. Finite Elements in Analysis and Design, 1990, 6, 303-320.

27. Lo, K. H., Christensen, R. M. and Wu, E. M., A higher-order theory of plate deformation I. Homogeneous plates. ASME Journal of Applied Mechanics, $1977,44,663-668$.

28. Hinton, E., Rock, T. and Zienkiewicz, O. C., A note on mass lumping and related processes in the finite element method. International Journal of Earthquake Engineering Structural Dynamics, 1976, 4, 245-249.

29. Marur, S. R. and Kant, T., A modified form of the central difference predictor scheme for damped nonlinear systems. Computers and Structures, 1994, 50, 615-618.

30. Chen, J. K. and Sun, C. T., Nonlinear transient responses of initially stressed composite plates. Computers and Structures, 1985, 21, 513-520.

31. Allen, H. G., Analysis and Design of Structural Sandwich Panels. Pergamon, London, 1969.

32. Reddy, J. N., On the solutions to forced motions of rectangular composite plates. ASME Journal of Applied Mechanics, 1982, 49, 403-408. 